\title{
Spatial variability analysis of reference evapotranspiration in Iran utilizing fine resolution gridded datasets
}

\author{
Tayeb Raziei ${ }^{\mathrm{a}, \mathrm{b}, *}$, Luis S. Pereira ${ }^{\mathrm{a}}$ \\ a CEER - Biosystems Engineering, Institute of Agronomy, Technical University of Lisbon, Portugal \\ b Soil Conservation and Watershed Management Research Institute (SCWMRI), Tehran, Iran
}

\section{A R T I C L E I N F O}

\section{Article history:}

Received 15 February 2013

Accepted 2 May 2013

Available online 1 June 2013

\section{Keywords:}

Reference evapotranspiration

Radiation adjustment coefficient

Temperature adjustment

Gridded datasets

Kriging

Spatial variability

\begin{abstract}
A B S T R A C T
Monthly averages of maximum and minimum temperature, mean relative humidity, sunshine duration and wind speed at $2 \mathrm{~m}$ height, relative to 148 Iranian weather stations and period 1991-2005 were utilized for interpolation and gridding the variables to $1^{\circ}$ in latitude and longitude. The Ordinary kriging method was used coupled with a spherical isotropic variogram. Monthly precipitation of the APHRODITE dataset was regridded to the same mesh grid for computing the aridity index jointly with the gridded variables. The required elevation for estimation of $\mathrm{ET}_{0}$ at each grid node was extracted from the digital elevation map of Iran. The adequacy of gridded variables was proved through a set of statistical indicators applied to the cross-validated interpolation errors. The Penman-Monteith (PM-ET $)$ reference evapotranspiration $\left(\mathrm{ET}_{0}\right)$ was estimated using the gridded variables and statistically compared with those of observational datasets

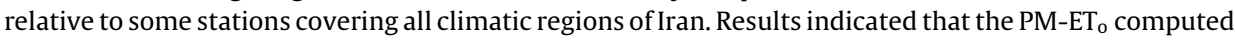
using gridded variables well fitted the $\mathrm{PM}-\mathrm{ET}_{0}$ computed using observed full weather variables at those selected stations. $\mathrm{ET}_{\mathrm{o}}$ was also estimated by the Hargreaves-Samani (HS) and FAO-PM temperature (PMT) methods using gridded variables of minimum and maximum temperature $\left(T_{\min }\right.$ and $T_{\max }$ ). To estimate $\mathrm{ET}_{\mathrm{o}}$ with $\mathrm{HS}$ and PMT methods, appropriate $k_{\mathrm{Rs}}$, an empirical radiation adjustment coefficient, were considered for each station, whereas $T_{\min }$ was adjusted for estimation of the dew point temperature $\left(T_{\text {dew }}\right)$ used for PMT computation. It was found that the appropriate $k_{\mathrm{Rs}}$ for both HS and PMT methods are identical all over the country and they are smaller in dry-sub-humid to humid areas and higher in semiarid to hyper-arid climates. The result suggested that the HS and PMT methods appropriately predict $\mathrm{ET}_{0}$ all over Iran if the appropriate $k_{\mathrm{Rs}}$ are utilized. The spatial patterns of $\mathrm{ET}_{\mathrm{o}}$ computed with HS and PMT

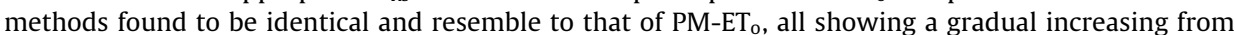
north to south, with the lowest $\mathrm{ET}_{\mathrm{o}}$ values observed over northern humid and sub-humid climates of Iran and larger $\mathrm{ET}_{0}$ for arid and hyper-arid climates in the southern and eastern country. Results indicated that the HS and PMT methods are appropriate alternatives for estimation of $\mathrm{ET}_{0}$ for all climatic regions of Iran, either when using observation or gridded data.
\end{abstract}

(c) 2013 Elsevier B.V. All rights reserved.

\section{Introduction}

An accurate estimation of reference evapotranspiration $\left(\mathrm{ET}_{0}\right)$ is essential for agricultural and hydrological studies, water resources management, watershed management and, more specificaly, for estimation of crop water requirements, supporting irrigation scheduling, drought management and climate change studies. The Penman-Monteith $\mathrm{ET}_{\mathrm{o}}\left(\mathrm{PM}-\mathrm{ET}_{\mathrm{o}}\right.$ ) equation proposed by Food and Agricultural Organization of United Nations (FAO), using grass as reference crop (Allen et al., 1998) has been successfully applied at different time scales in various climatic regions of the world

\footnotetext{
* Corresponding author. Tel.: +351 213653480.

E-mail addresses: tayebrazi@yahoo.com (T. Raziei), lspereira@isa.utl.pt (L.S. Pereira).
}

(Pereira et al., 1999; Smith, 2000; Allen et al., 2006). The PM-ET equation requires solar radiation data or sunshine duration for estimating net radiation $\left(R_{\mathrm{n}}\right)$, maximum and minimum temperature ( $T_{\max }$ and $T_{\min }$, respectively), psychrometric or relative humidity (RH) data for estimating the vapour pressure deficit (VPD), and wind speed $(U)$. The parameters of PM-ET $\mathrm{E}_{0}$ can be computed appropriately following the procedures proposed by Allen et al. (1998) and revisited by Nandagiri and Kovoor (2005) and Gong et al. (2006). Using appropriate approaches it is possible to accurately compute $\mathrm{ET}_{\mathrm{o}}$ with limited data such as with $T_{\max }$ and $T_{\min }$ only as demonstrated in previous papers applied to Iran (Raziei and Pereira, 2013), the Mediterranean region (Todorovic et al., 2013) and other regions (Popova et al., 2006; Cai et al., 2009). Nevertheless, to adequately estimate $\mathrm{ET}_{0}$ for a given area a dense station network providing the required weather datasets is essential. However, the required full weather datasets for estimation of PM-ET 
are lacking in many parts of the world, particularly in remote areas, that limits the application of PM-ET

Due to the complex orography and wide latitudinal extent (Fig. 1a), Iran comprises diverse climates ranging from very humid in the Caspian Sea region to arid and hyper arid in the central, southern and eastern Iran. Therefore, to have a spatially comprehensive analysis of $\mathrm{ET}_{0}$ for Iran, a dense network of weather stations measuring the required variables for $\mathrm{ET}_{0}$ estimation is essential. Contrarily, the distribution of the available meteorological stations in most parts of Iran is irregular and sporadic, particularly in central-eastern country where the stations are quite sparse. This irregularity are more pronounced from 1981 backward, particularly relative to sunshine duration, relative humidity and wind

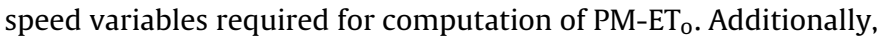
the considered variables suffer from substantial missing values that makes difficult and less reliable their use for $\mathrm{ET}_{0}$ estimation, although the computation of $\mathrm{ET}_{\mathrm{o}}$ for Iran using a dense and uniform distributed station network or a gridded dataset is desirable and of paramount importance for agricultural and water resources management practices in the region.

There are some global scale fine resolution gridded datasets developed with the aim of being used in investigation of climate pattern analysis as well as in studying the spatial variability of evapotranspiration and drought. The most well known monthly gridded datasets at global scale are the Climatic Research Unit (CRU) datasets (http://www.cru.uea.ac.uk/cru/data), the Global Precipitation Climatology Project (GPCP) (Adler et al., 2003, http://precip.gsfc.nasa.gov) and the worldclim dataset (Hijmans et al., 2005, http://www.worldclim.org). The inverse distance weighting (IDW, Jones et al., 1986), the Shepard method (Shepard, 1968) and the Kriging and Splines (Hutchinson, 1995) are the most popular and widely used techniques utilized to produce the most well-known global and continental scales gridded datasets. The IDW is based on the assumption that the climatic value at unsampled points is a distance weighted average of the climatic values at the nearby sampling points. Similarly, the method of Shepard uses an inverse distance weighted algorithm, but differently it uses least squares method to eliminate or reduce the bull's eye appearance in the generated contours. The Kriging method is a collection of linear regression methods that takes into account the stochastic nature of the data using a parametric variogram function to model the spatial correlation, thus involving the development of one or more semivariogram models that best fit the data to arrive at optimum station weights for interpolation (Daly et al., 2002). Spline is also a statistical interpolator closely linked to Kriging with comparative results (Laslett, 1994). It produces smoothed surfaces, and therefore is most useful for application in global or continental scales interpolation (e.g., New et al., 1999). However, the performance of these methods varies as a function of various factors, including the temporal and spatial scale and the density of stations (Hofstra et al., 2008) as well as the climatic differences among locations used in interpolation.

More recently, daily gridded precipitation datasets have been developed for Europe (E-OBS dataset, Haylock et al., 2008), North America (Maurer et al., 2002), South America (Liebmann and Allured, 2005), Asia (Yatagai et al., 2009), Spain (Herrera et al. 2012) and Portugal (Belo-Pereira et al., 2011) using dense networks of observatories. Though the CRU dataset provides the 1961-1990 climate normals for sunshine and wind speed at a very coarse spatial resolution of $10^{\circ}$ latitude $\times 10^{\circ}$ longitude at global scale (New et al., 2002), none of the available gridded datasets provides sunshine and wind speed time series at fine spatial resolution to be used in $\mathrm{ET}_{\mathrm{o}}$ estimation. Therefore, it is desirable to develop a fine resolution gridded datasets for Iran using as much as available observatories across the country to provide the required variables for $\mathrm{ET}_{\mathrm{o}}$ estimation as well as for drought variability analysis using variants of the Palmer Drought Severity Index including its modified version for Mediterranean conditions (MedPDSI, Pereira et al., 2007) or the Reconnaissance Drought Index (RDI, Tsakiris et al., 2007).

The present study aims to develop a gridded datasets at $1^{\circ}$ latitude $\times 1^{\circ}$ longitude spatial resolution using data records relative to 148 Iranian weather stations relatively regularly distributed over the country, to be used for estimation of $\mathrm{ET}_{\mathrm{O}}$ at a fine spatial resolution over Iran, including using estimation methods requiring $T_{\max }$ and $T_{\min }$ only. Differently from other studies assessing the accuracy of various equations for $\mathrm{ET}_{\mathrm{o}}$ estimation using limted weather data, this study aims to accurately produce gridded weather data sets for $\mathrm{ET}_{\mathrm{o}}$ computation and assesses the spatial variability of $\mathrm{ET}_{\mathrm{o}}$ computed with both full and limited weather data at country scale.

\section{Material and methods}

\subsection{Data}

The required variables for computation of $\mathrm{ET}_{\mathrm{o}}$ at monthly time scale, i.e., monthly averages of $T_{\max }$ and $T_{\min }$, mean $\mathrm{RH}$, sunshine duration and wind speed at $2 \mathrm{~m}$ height relative to 148 Iranian weather stations distributed over the country (Fig. 1b) were utilized for interpolation and gridding the considered variables at a fine spatial resolution of $1^{\circ}$ latitude $\times 1^{\circ}$ longitude. The required variables, particularly sunshine duration and wind speed, are measured at irregularly spaced locations over the country for the period before 1990 , suffering also from substantial missing values. This situation limits computation of $\mathrm{ET}_{0}$ over the country, aiming to analyse long-term time variability of $\mathrm{ET}_{0}$, including to assess possible influences of climate change. Differently, all the Iranian synoptic and climatic weather stations have complete data records from 1991 onward, being quite suitable and appropriate for a comprehensive analysis of spatial variability and regionalization of $\mathrm{ET}_{\mathrm{o}}$ across Iran. The stations considered for the present study are relatively regularly distributed through the country (Fig. 1b), particularly in western and northern areas where the station networks are favourably dense. The climatic records passed a careful quality control by the Iranian meteorological organization and encompassed very rare missing values in the selected time period (1991-2005). The observed missing values at a few stations were more concentrated in 1991 and mostly correspond to the sunshine and wind speed records. Table 1 shows the number of used stations available each year for gridding the variables; it is evident that the number of stations used for gridding sunshine duration and wind speed are relatively smaller and scattered than those for $T_{\max }, T_{\min }$ and $\mathrm{RH}$ variables. The time series of the variables were investigated for possible non-homogeneities by comparing the time series of a

Table 1

Number of stations used for gridding the variables.

\begin{tabular}{llllll}
\hline Year & $T_{\max }$ & $T_{\min }$ & $\mathrm{RH}$ & Sunshine & Wind speed \\
\hline 1991 & 140 & 140 & 118 & 116 & 118 \\
1992 & 146 & 146 & 121 & 128 & 125 \\
1993 & 146 & 147 & 137 & 116 & 133 \\
1994 & 145 & 143 & 137 & 128 & 140 \\
1995 & 147 & 148 & 146 & 143 & 145 \\
1996 & 148 & 148 & 147 & 147 & 147 \\
1997 & 148 & 148 & 146 & 147 & 147 \\
1998 & 148 & 148 & 147 & 147 & 147 \\
1999 & 148 & 148 & 148 & 147 & 148 \\
2000 & 148 & 148 & 148 & 145 & 148 \\
2001 & 148 & 148 & 148 & 146 & 148 \\
2002 & 148 & 148 & 145 & 143 & 148 \\
2003 & 148 & 148 & 148 & 147 & 148 \\
2004 & 144 & 144 & 141 & 141 & 142 \\
2005 & 144 & 144 & 142 & 141 & 142 \\
\hline
\end{tabular}



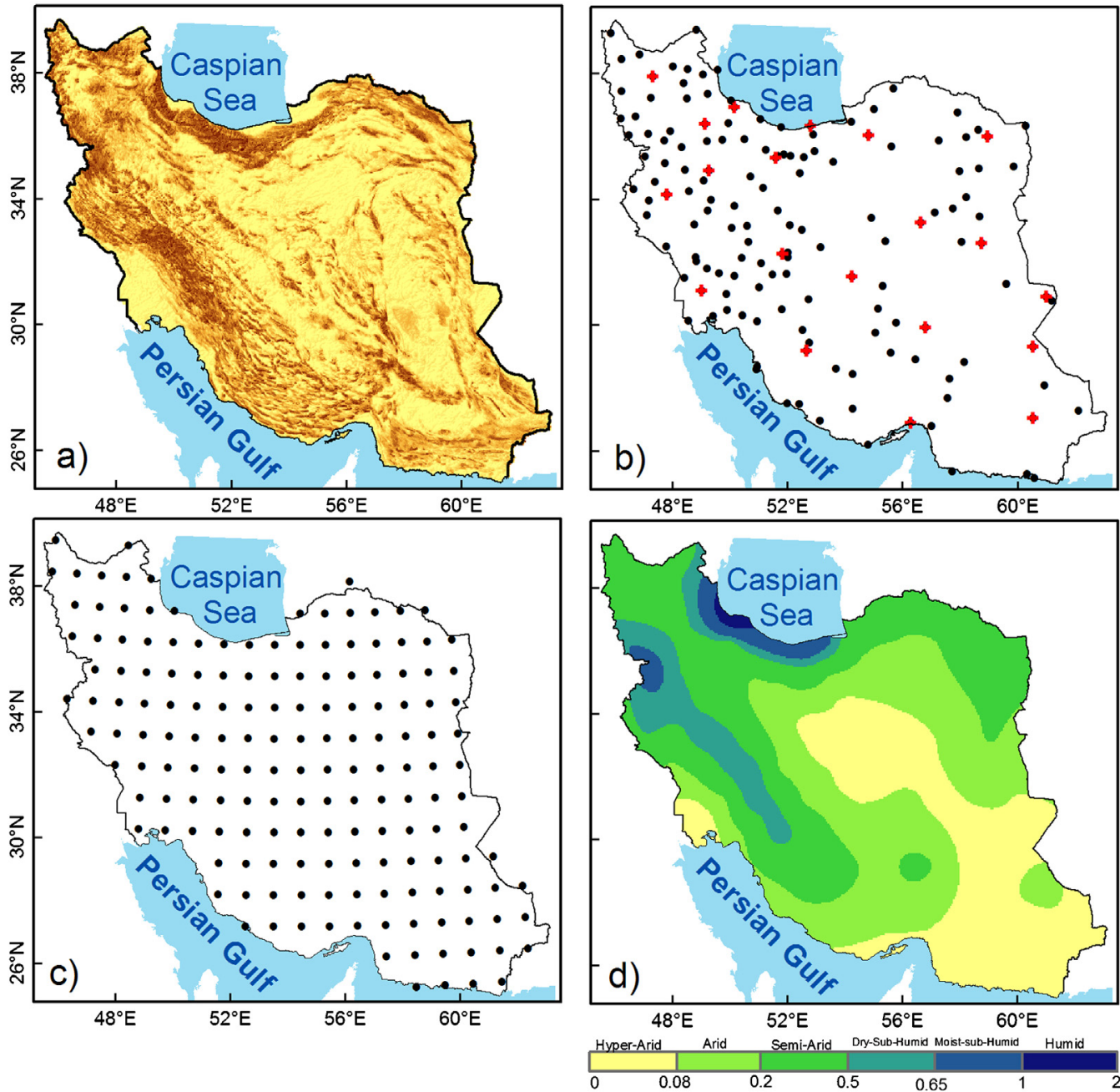

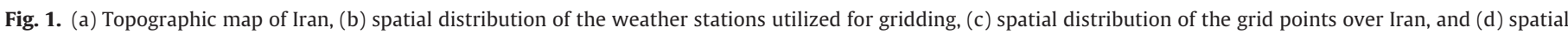

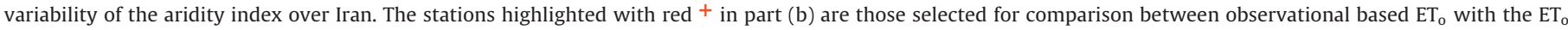
computed using gridded variables.

given station with those of neighbouring stations; the result proved that all the variables were homogeneous in the chosen time period. To estimate few observed missing monthly climatic data, a spatial method (Perry and Hollis, 2005) was used by which the missing values at a single point were estimated through the gridding procedure based on all data available for a single month, taking into account both the relative positions of sampling points and their distances.

The Digital Elevation Model (DEM) map of Iran (Fig. 1a), extracted from satellite images of the Advanced Spaceborne Thermal Emission and Reflection Radiometer (ASTER) developed by joint cooperation between NASA and Japan's Ministry of Economy, Trade and Industry (METI), and Japan Space Systems was used to extract the elevation of the grid points in order to be used for estimation of $\mathrm{ET}_{\mathrm{o}}$ at each grid node (Fig. 1c).

\subsection{Interpolation and gridding procedure}

To develop the gridded dataset of the climate variables considered in the present study, we have used the Ordinary Kriging (OKrig) method as appropriate interpolator since it is simple and widely used for gridding many geophysical fields (Matheron, 1971; Biau et al., 1999). OKrig was used by Belo-Pereira et al. (2011) and Herrera et al. (2012) for climate gridding purposes, assuming that the mean is unknown, thus focusing on the spatial component and using only the samples in the local neighbourhood for the estimate. Since Kriging takes into account both the relative positions of sampling points and their distances from the interpolated point (Dirks et al., 1998), it may be the most accurate method for interpolation in areas with low resolution networks, as is the case for the stations network in the present study (Fig. 1b). It is also a very appropriate method when there is not a strict confidence on the data measurements. Moreover, this method produces visually appealing surface plots from irregularly spaced data to express existent trends in the dataset, so that high points might be connected along a ridge rather than isolated by bull's-eye type contours. The OKrig method is the simplest form of Kriging and is less sensitive to the density of observations network (Belo-Pereira et al., 2011); it assumes that data are stationary, i.e. they contain no significant trends (or drifts) over the spatial range (Journel and Huijbregts, 1978). However, many regionalized variables show local trends or even broader regional trends when spatially analysed. These trends are usually not a problem because the stationarity assumption applies only to the search neighbourhood used in the interpolation, which may be reasonably homogeneous, and not to the entire data set (Holdaway, 1996). Moreover, the considered time scale (monthly) and the climatic variables used in this study make the variables to be nearly stationary in time and in space when compared to daily variables 
(Shen et al., 2001). However, problems still occur for the wind speed variable, particularly in the southern regions, due to its extreme variability. Gridding wind speed data consists of the main limitation of this study. It is worth nothing that the utilization of the OKrig method in the present study inexplicitly includes the role of topography since the stations network are representative of a wide range of elevation variability and geographic features of Iran (Fig. 1a and b).

The spatial variability of the data points as a function of distance was evaluated through inspection of the experimental variograms for all considered months and variables using GS+ software (http://www.gammadesign.com). Inspection of the experimental variograms relative to all the variables and months suggested that the spherical isotropic model most often best fitted the experimental variograms. Therefore, to minimize computation procedure, a separate variogram was fitted to the long-term mean of each variable and individual month, i.e., the fitted variogram for each variable has the same form for each month regardless of the year, assuming that the spatial variability of the variable has not changed over the 1991-2005 time period (Holdaway, 1996).

\subsection{Evaluation of gridding procedures}

The accuracy and performance of the interpolation method was first assessed by carrying out a cross-validation. To do so, for each month, the climate variables for each station were estimated after excluding that station from the input data. This process was repeated for all the stations, with each removed station being reinserted back into the network after it has been interpolated (Willmott and Mastuura, 1995; Holdaway, 1996). The differences between the estimated (cross validated) and observed values, i.e., residuals or errors, were analysed.both spatially and temporally to examine the accuracy of the interpolation as a function of time and space and to examine if the errors show any spatial trend. The empirical distribution of the cross-validated errors associated to the considered variables were evaluated to quantify the degree of imprecision in the interpolation result, i.e. the uncertainty of the interpolation method was assessed by examining the proportion of the errors that fall within the 95\% confidence interval of the fitted normal distribution (Philips and Marks, 1996).

The interpolation errors were further evaluated using the Willmott (1981) index of agreement, $d_{\mathrm{IA}}$, to examine the degree of agreement between observations and estimations for a given map. As such, for each month and variable, the prediction error was aggregated over all the stations to express the index of agreement. The $d_{I A}$ index is a non-dimensional measure that represents the ratio between the mean square error and the potential error, defined as the sum of the squared absolute values of the distances from the predicted values to the mean observed value and distances from the observed values to the mean observed value (Willmott, 1981; Moriasi et al., 2007):

$$
d_{\mathrm{IA}}=1-\frac{\sum_{i=1}^{n}\left(O_{i}-P_{i}\right)^{2}}{\sum_{i=1}^{n} 2\left(\left|P_{i}-\bar{O}\right|+\left|O_{i}-\bar{O}\right|\right)^{2}}
$$

where $P_{i}$ and $O_{i}$ are respectively the interpolated and observed values for a given station, $n$ is the number of stations used for interpolation for each map, and $\bar{O}$ is the associated mean of the observed values at the considered stations. $d_{\mathrm{IA}}$ varies between 0 and 1 ; a value of 1 indicates a perfect agreement between the observed and interpolated values, while 0 indicates no agreement at all (Willmott, 1981; Moriasi et al., 2007). As a non-dimensional measure, the $d_{\mathrm{IA}}$ index is a useful tool to evaluate the accuracy of the interpolation estimation. The monthly variation of the $d_{\mathrm{IA}}$ corresponding to all considered variables were compactly represented by box-Whisker plots to investigate the stability of the interpolation performance as a function of time.

In order to re-evaluate the performance of gridding datasets to

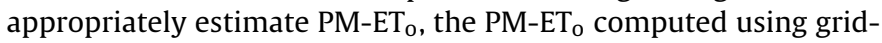
ded datasets was compared with the estimated $\mathrm{PM}^{-\mathrm{ET}_{0}}$ using full observational datasets for some selected stations distributed over the country (Fig. 1b). This step of performance evaluation is very crucial in examining the propagation of estimation errors relative

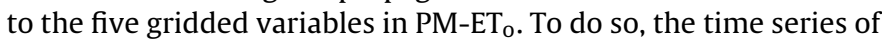
the estimated $\mathrm{PM}-\mathrm{ET}_{\mathrm{o}}$ for the selected stations were statistically compared with that of gridded datasets averaged over the grid points surrounding a given station. With this objective, the root mean square error, RMSE and the modelling efficiency, EF, were used in addition to the $\mathrm{d}_{\mathrm{IA}}$ index (Nash and Sutcliffe, 1970; Moriasi et al., 2007). The RMSE characterizes the variance of the errors; the smaller RMSE the better is the model's performance. EF determines the relative magnitude of the residual variance comparatively to the measured data variance; as in Eq. (2), it is defined from the ratio of the mean square error to the variance in the observed data. $\mathrm{EF}$ indicates that when the residual variance equals the observed data variance it results $\mathrm{EF}=1.0$; contrarily, when $\mathrm{EF}$ equals zero or is negative this indicates that the observed mean $\bar{O}$ is as good or better predictor than the model.

$$
\mathrm{EF}=1-\frac{\sum_{i=1}^{n}\left(O_{i}-P_{i}\right)^{2}}{\sum_{i=1}^{n}\left(O_{i}-\bar{O}\right)^{2}}
$$

\subsection{ET $T_{o}$ estimation methods}

The PM-ET evapotranspiration, i.e., the rate of evapotranspiration from a hypothetical crop with an assumed fixed height $(12 \mathrm{~cm})$, daily surface resistance $\left(70 \mathrm{~s} \mathrm{~m}^{-1}\right)$ and albedo $(0.23)$, approximately resembling the evapotranspiration from an extensive surface of a disease-free green grass cover of uniform height, actively growing, completely shading the ground, and with adequate water and nutrient supply (Allen et al., 1998). The PM-ET ${ }_{0}$ equation for calculation of daily $\mathrm{ET}_{0}$ takes the form:

$\mathrm{ET}_{\mathrm{o}}=\frac{0.408 \Delta\left(R_{\mathrm{n}}-G\right)+\gamma \frac{900}{T+273} u_{2}\left(e_{\mathrm{s}}-e_{\mathrm{a}}\right)}{\Delta+\gamma\left(1+0.34 u_{2}\right)}$

where $\mathrm{ET}_{\mathrm{o}}$ is the grass reference evapotranspiration [ $\mathrm{mm} \mathrm{day}^{-1}$ ], $R_{\mathrm{n}}$ is the net radiation at the crop surface [MJ m$\left.{ }^{-2} \mathrm{day}^{-1}\right], G$ is soil heat flux density $\left[\mathrm{MJ} \mathrm{m}^{-2}\right.$ day $\left.^{-1}\right], T$ is mean daily air temperature at $2 \mathrm{~m}$ height $\left[{ }^{\circ} \mathrm{C}\right], u_{2}$ is wind speed at $2 \mathrm{~m}$ height $\left[\mathrm{m} \mathrm{s}^{-1}\right], e_{\mathrm{s}}$ is saturation vapour pressure [ $\mathrm{kPa}], e_{\mathrm{a}}$ is actual vapour pressure [kPa], $e_{\mathrm{s}}-e_{\mathrm{a}}$ is vapour pressure deficit [ $\mathrm{kPa}], \Delta$ is the slope of the vapour pressure curve $\left[\mathrm{kPa}{ }^{\circ} \mathrm{C}^{-1}\right]$, and $\gamma$ is the psychometric constant $\left[\mathrm{kPa}{ }^{\circ} \mathrm{C}^{-1}\right]$. This equation uses standard meteorological records of solar radiation or sunshine duration, minimum and maximum air temperature, air humidity and wind speed. To ensure the integrity of computations, the weather measurements should be made at $2 \mathrm{~m}$ (or converted to that height) above an extensive surface of green grass, shading the ground and not short of water. The parameters of Eq. (3) can be estimated from the observed climatic variables following the standard methods proposed by Allen et al. (1998).

Net radiation $\left(R_{\mathrm{n}}\right)$ is computed as the algebraic sum of the net short wave radiation $\left(R_{\mathrm{ns}}\right)$ and the net long wave radiation $\left(R_{\mathrm{nl}}\right): R_{\mathrm{ns}}$, results from the balance between incoming and reflected solar radiation $\left(R_{\mathrm{S}}\right)$ adopting an albedo of 0.23 for the grass reference crop. $R_{\mathrm{nl}}$ 
results from the balance between the down-coming and the outgoing long wave radiation emitted by the vegetation and the soil. Computations were performed as proposed by Allen et al. (1998). When $R_{\mathrm{S}}$ is not measured, it can be estimated from the observed sunshine duration with the Angström (1924) equation:

$R_{\mathrm{s}}=\left(a_{\mathrm{s}}+b_{\mathrm{s}} \frac{n}{N}\right) R_{\mathrm{a}}$

where $R_{\mathrm{S}}$ is solar or shortwave radiation [MJ m $\mathrm{m}^{-2} \mathrm{day}^{-1}$ ], $n$ is actual duration of sunshine [h], $N$ is maximum possible duration of sunshine or daylight hours [h], $n / N$ is relative sunshine duration [-], $R_{\mathrm{a}}$ is extraterrestrial radiation [ $\left[\mathrm{MJ} \mathrm{m}^{-2}\right.$ day $\left.^{-1}\right], a_{\mathrm{s}}$ is the coefficient expressing the fraction of extraterrestrial radiation reaching the earth on overcast days $(n=0)$, and $a_{\mathrm{s}}+b_{\mathrm{s}}$ is the fraction of extraterrestrial radiation reaching the earth on clear sky days $(n=N)$. The values $a_{\mathrm{s}}=0.25$ and $b_{\mathrm{s}}=0.50$ are recommended when these fractions are not calibrated using a set of good quality data on both $n / N$ and $R_{\mathrm{s}}$. Extraterrestrial radiation $R_{\mathrm{a}}$ and daylight hours $N$ are computed for any given day as a function of the latitude of the site (Allen et al., 1998).

$R_{\mathrm{S}}$ may be computed from temperature data only (Allen et al., 1998) as:

$R_{\mathrm{S}}=k_{\mathrm{Rs}} \sqrt{\left(T_{\max }-T_{\min }\right)} R_{\mathrm{a}}$

where $k_{\mathrm{Rs}}$ is the empirical radiation adjustment coefficient $\left[{ }^{\circ} \mathrm{C}^{-0.5}\right.$ ] whose values for Iran are spatially distributed as reported by Raziei and Pereira (2013): $k_{\mathrm{Rs}}$ for the stations located in sub-humid to humid climates varied between 0.10 and 0.18 , while they ranged from 0.11 to 0.20 for the stations situated in the semi-arid to hyperarid climates.

VPD was estimated as the difference between the saturation and the actual vapour pressure ( $e_{\mathrm{s}}$ and $e_{\mathrm{a}}$ respectively). Saturation vapour pressure is computed as the average of $e^{o}\left(T_{\max }\right)$ and $e^{o}\left(T_{\min }\right)$. When using mean relative humidity $\left(\mathrm{RH}_{\text {mean }}\right)$, the actual daily vapour pressure $e_{\mathrm{a}}$ is computed as (Allen et al., 1998):

$e_{\mathrm{a}}=\frac{\mathrm{RH}_{\text {mean }}}{50 / e^{\mathrm{o}}\left(T_{\min }\right)+50 / e^{\mathrm{o}}\left(T_{\max }\right)}$

In the absence of humidity data, $e_{\mathrm{a}}$ may be obtained by assuming that the dew point temperature, $T_{\mathrm{dew}}$, is close to the daily minimum temperature, $T_{\min }$ :

$e_{\mathrm{a}}=e^{\mathrm{o}}\left(T_{\min }\right)=0.611 \exp \left[\frac{17.27 T_{\min }}{T_{\min }+237.3}\right]$

However, if the weather station cannot be considered a reference site, where $T_{\mathrm{dew}}=T_{\min }$, corrections for $T_{\min }$ are necessary as discussed by Raziei and Pereira (2013).

When wind speed is not available, using an average regional wind speed value, or just the world average value of $2 \mathrm{~m} \mathrm{~s}^{-1}$, is generally appropriate but may be questionable for arid and hyper-arid regions when high wind speed occurs (Raziei and Pereira, 2013).

A combination of estimations using Eqs. (5) and (7) with an estimate of wind speed leads to the possible use of Eq. (3) using only temperature data, the so called PM temperature method (PMT). Eq. (3) may also be used adopting estimations by Eqs. (5) and/or (7) when respectively radiation and/or humidity data are missing (Popova et al., 2006). In alternative, the Hargreaves and Samani (1985) equation (HS) may be used because it requires only observed $T_{\min }$ and $T_{\max }$ for the estimation of $\mathrm{ET}_{\mathrm{o}}\left[\mathrm{mm}_{\mathrm{day}}{ }^{-1}\right]$, which is given as:

$\mathrm{ET}_{\mathrm{o}}=0.0135 k_{\mathrm{Rs}} \frac{R_{\mathrm{a}}}{\lambda} \sqrt{\left(T_{\max }-T_{\min }\right)}(T+17.8)$

where $R_{\mathrm{a}}$ is the extraterrestrial radiation as defined earlier, and $\lambda$ is the latent heat of vaporization $\left[\mathrm{MJ} \mathrm{kg}^{-1}\right.$ ] for the mean air temperature $T\left[{ }^{\circ} \mathrm{C}\right.$, that is commonly assumed equal to $2.45 \mathrm{MJ} \mathrm{kg}^{-1} .0 .0135$
Table 2

Correction of $T_{\text {dew }}$ estimates from $T_{\min }$ for estimation of actual vapour pressure.

\begin{tabular}{lll}
\hline Climate zones & Annual $\mathrm{P} / \mathrm{ET}_{\mathrm{o}}$ & Corrected $T_{\mathrm{dew}}\left({ }^{\circ} \mathrm{C}\right)$ \\
\hline Hyper-arid & $<0.08$ & $T_{\mathrm{dew}}=T_{\min }-4$ \\
Arid & $0.08-0.20$ & $T_{\mathrm{dew}}=T_{\min }-2$ \\
Semi-arid & $0.20-0.50$ & $T_{\mathrm{dew}}=T_{\min }-1$ \\
Dry sub-humid & $0.50-0.65$ & $T_{\mathrm{dew}}=T_{\min }-1$ \\
Moist sub-humid & $0.65-1.0$ & No correction for aridity \\
Humid & $>1.0$ & No correction for aridity \\
\hline
\end{tabular}

is a factor for conversion from American to the International system of units and $k_{\mathrm{Rs}}$ is the radiation adjustment coefficient defined in Eq. (5). In the application to Iran (Raziei and Pereira, 2013), $k_{\mathrm{Rs}}$ was found to vary similarly with the values estimated for the PMT using Eq. (5), i.e., between 0.13 and 0.18 , in the sub-humid to humid climates and 0.14 and 0.20 for the stations situated in the semi-arid to hyper-arid climates.

The aridity map of Iran developed by Raziei and Pereira (2013) was updated herein using the gridded variables (Fig. 1d) to characterize the grid points with respect to the global aridity index (UNEP, 1997) which is required for adjusting minimum temperature for estimation of PMT as described in Section 2.5, Table 2 and Eq. (9). The UNEP aridity index consists of the ratio of mean annual precipitation $(\mathrm{P})$ to mean annual potential evapotranspiration computed with the Thornthwaite method (Thornthwaite, 1948). To compute the aridity index for the considered grid points (Fig. 1c) monthly precipitation corresponding to the ground based Asian Precipitation-Highly-Resolved Observational Data Integration Towards the Evaluation of Water Resources (APHRODITE) project for the Middle East (Yatagai et al., 2008, 2009) were regridded to the same mesh grid as in Fig. 1c. As in Raziei and Pereira (2013), the updated map of aridity index shown in Fig. 1d points to the humid and sub-humid climates over coastal areas of the Caspian Sea in northern Iran. Dry-sub-humid climate features occur in the highest parts of the Alborz mountain chain in the north, thus acting as a transitional band, isolating humid and sub-humid climates of the coastal areas of the Caspian Sea from the semi-arid areas of interior Iran. The dry-sub-humid climate also characterizes a remarkable part of western Iran over a narrow band of the highest mountains along the Zagros mountain chain, due to its relatively high annual precipitation accompanied with cold winters and moderate summers. Semi-arid climates refer to the mountainous areas of western, northern and north-eastern Iran, whereas arid and hyper-arid climates dominate central, southern and eastern Iran (Fig. 1d). In comparison to the previous study (Raziei and Pereira, 2013), the dry sub-humid climate appears dominant over the highest part of Zagros mountain ranges in western Iran, whereas the hyper-arid climate features central and south-eastern country as well as a small area in south-western Iran.

\subsection{Performance evaluation of HS and PMT methods}

As in Raziei and Pereira (2013) a trial and error procedure was applied to all data sets to find the best values for $k_{\mathrm{Rs}}$ since the relations proposed by Samani $(2000,2004)$ did not show to be appropriate. PMT computations were also performed with temperature correction for aridity effects as in Table 2 or for humidity impacts on $T_{\text {dew }}$ as proposed by Todorovic et al. (2013) and Raziei and Pereira (2013):

$T_{\text {dew }}=\left(\left(T_{\min }+T_{\max }\right) / 2\right)-a_{\mathrm{d}}$

with $a_{\mathrm{d}}=2^{\circ} \mathrm{C}$ for the months when $0.8<\mathrm{P} / \mathrm{ET}_{0}<1.0$ and $a_{\mathrm{d}}=1^{\circ} \mathrm{C}$ if $\mathrm{P} / \mathrm{ET}_{0}>1.0$.

The results of $\mathrm{ET}_{\mathrm{o}}$ estimated by PMT and HS methods using limited weather data were compared with those of reference PM$\mathrm{ET}_{\mathrm{O}}$ computed using full datasets. To assess the performance of HS 
and PMT methods with respect to PM-ET, relative to all pairs of observed and predicted values for each grid point, in addition to the coefficient of determination $\left(R^{2}\right)$ of a linear regression forced to the origin, the modelling efficiency (EF) and the index of agreement, $\left(d_{\mathrm{IA}}\right)$ were used. These indicators are briefly explained in Section 2.3 and their equations are given in literature, e.g., the comparative study of $\mathrm{ET}_{\mathrm{o}}$ models by Todorovic et al. (2013).

\section{Results}

\subsection{Performance of the interpolation}

Fig. 2 illustrates the distribution of the cross-validated errors of the variables with the fitted normal distribution. The figure suggests that the interpolation errors associated to the considered variables are centred around zero and are approximately normally distributed, thus indicating that the interpolated results preserved relatively well the original distribution of the variables. For all the variables, the majority of interpolation errors (more than $80 \%$ ) fall within the $95 \%$ confidence interval, indicating that the estimations are generally close to the observations, which is an indication of reasonably accurate interpolation.

The monthly variation of computed $\mathrm{d}_{\mathrm{IA}}$ index for all the variables are represented in Fig. 3 through box-Whisker plots to illustrate the performance of the interpolation method. Fig. 3a and 3b show monthly variations of $d_{\mathrm{IA}}$ for $T_{\max }$ and $T_{\min }$, respectively; they show that $d_{\mathrm{IA}}$ mostly lies above 0.95 for both variables, which indicates a very good agreement between estimations and observations. However, the degree of agreement varies among months, with the highest agreement in winter and lowest in summer. The noticeable lower agreement in summer months may be attributed to the more localized and independent temperature characteristics due to substantial topographic effects on temperature and developing microclimates in this season, thus reducing the spatially consistencies of the variables. Though the monthly variation of $d_{\mathrm{IA}}$ index for
$T_{\max }$ and $T_{\min }$ are identical, the estimation error is slightly higher for the later variable because it is more sensitive to local climate and advection.

Fig. 3c suggests that the estimated values for mean $\mathrm{RH}$ are in good agreement with the observed ones; a larger estimation error from December to March indicates that $\mathrm{RH}$ is more heterogeneous in space during winter than in summer. This may be explained by the intrusion of variable sources of humid air into different parts of Iran by different atmospheric circulation types in winter (Raziei et al., 2012a, 2012b). However, contrarily to temperature variables, the estimation error for sunshine (Fig. 3d) is highly variable (wider spread for the $25-75 \%$ percentiles) during all months, though in most cases the lower quartile of the box plot of $d_{\mathrm{IA}}$ lies above 0.90 , thus pointing to a satisfactory accuracy of interpolation. This variability may also relate to the influence of different atmospheric circulation types in differentiating the target area regarding to clearness/cloudiness of the sky across the country. Dust storms should also be considered as another responsible factor in differentiating the clearness of the sky in arid and hyper-arid climates of central, eastern and southern Iran, even in very short distances. This phenomenon may cause a noticeable underestimation of sunshine duration in some stations due to obscuring the sunshine recorder, resulting in a noticeable reduction in sunshine records that may locally be far different from the neighbouring sites. As is illustrated in Fig. 3e, the estimation error is noticeably high for interpolation of wind speed, resulting in much lower $d_{\mathrm{IA}}$ values in comparison to the other variables shown in Fig. 3a-d. The higher estimation error for wind speed is likely to be due to the fact that wind speed is highly variable in space as it is a locally dependent variable, thus causing it to be highly spatially non-continuous even in short distances. Wind speed varies much throughout the country and the respective spatial pattern shows a large local dependency as analysed in a former study on $\mathrm{ET}_{\mathrm{o}}$ (Raziei and Pereira, 2013). This characteristic can be related to the substantial effect of the topography, that can induce changes in wind speed and direction in short
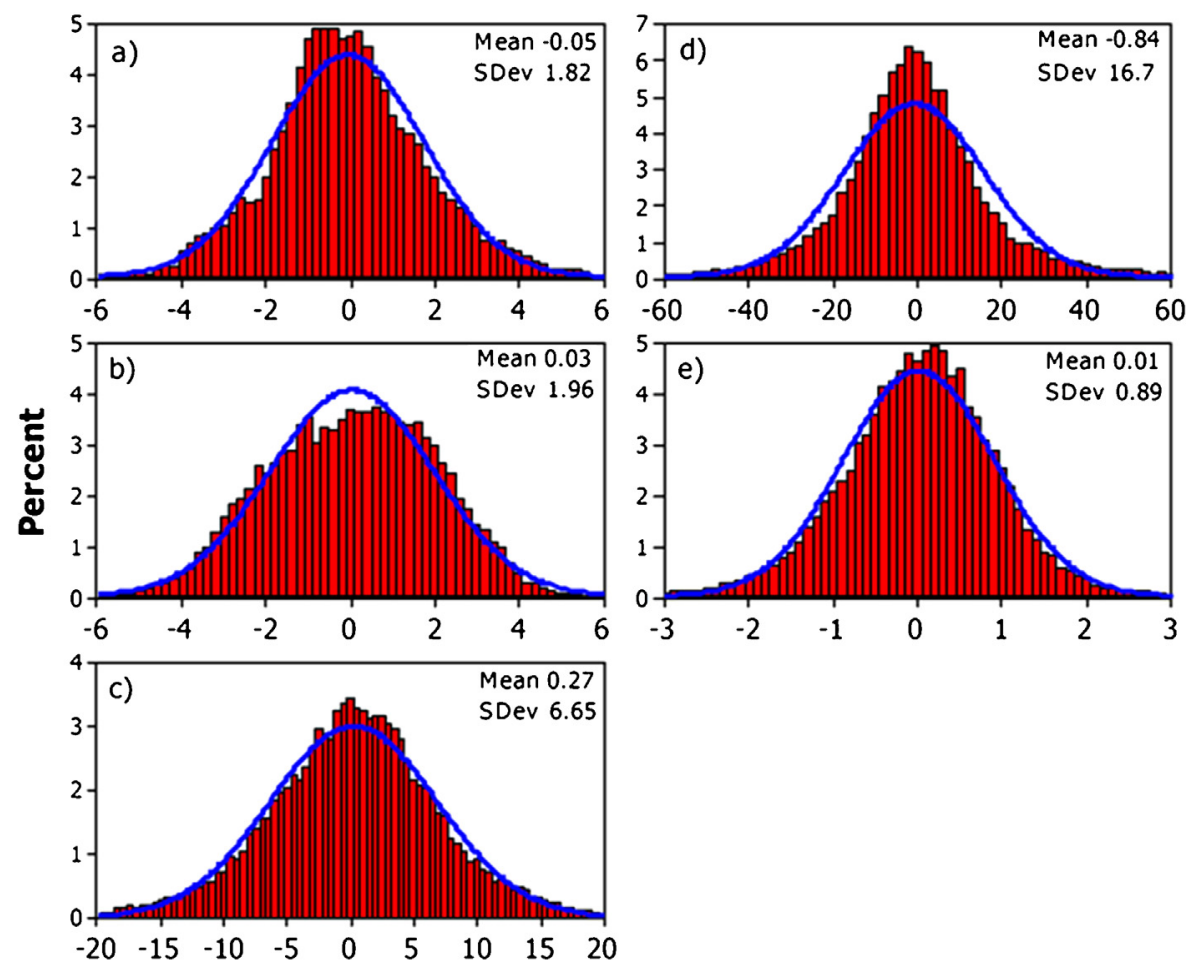

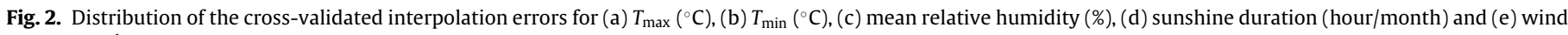
speed $\left(\mathrm{m} \mathrm{s}^{-1}\right)$. The values on the graphs are the means and standard deviations of the errors. 

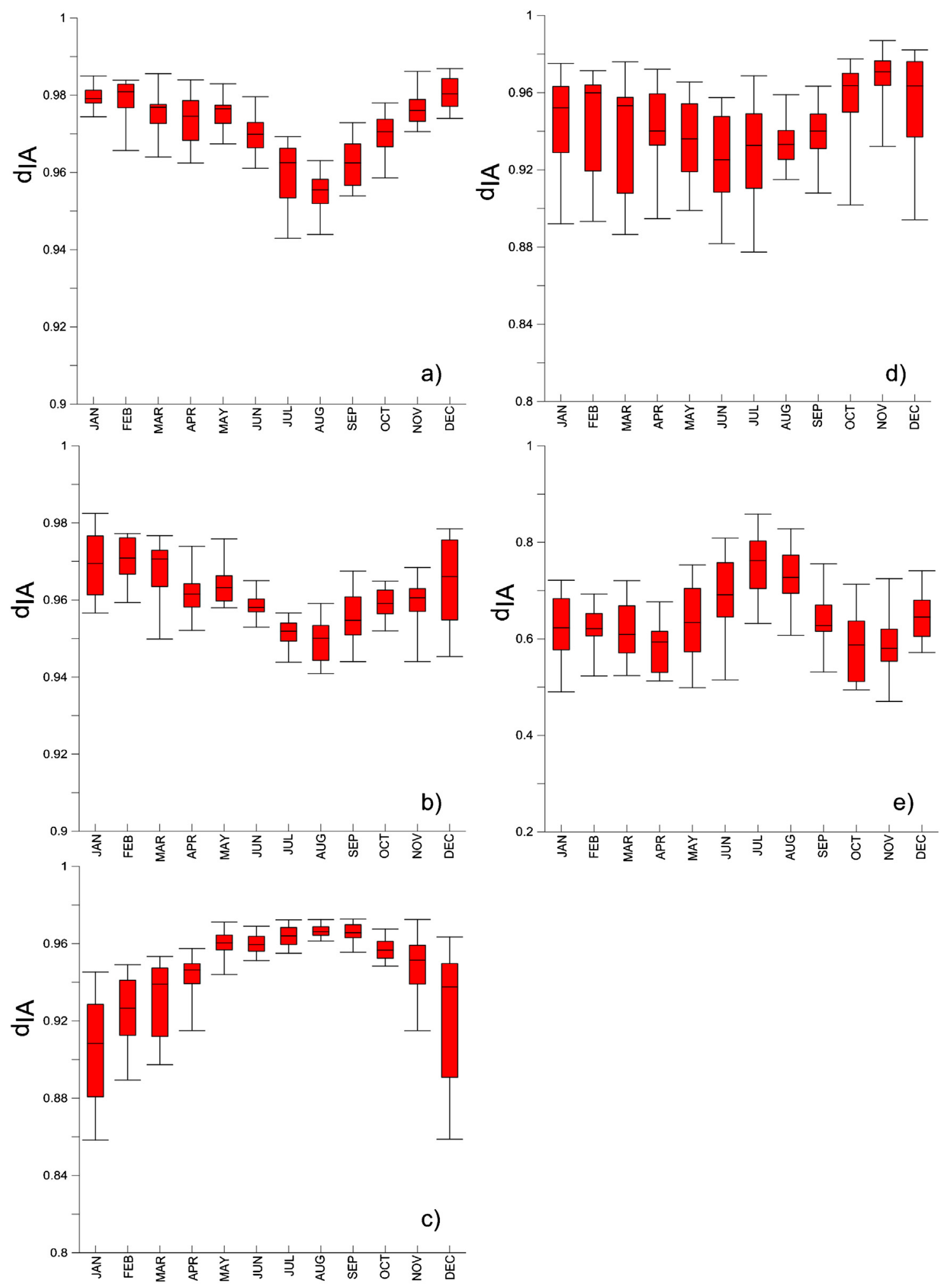

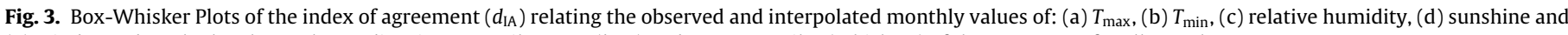
(e) wind speed. Each plot shows the median, interquartile range (box) and outer quartiles (whiskers) of the agreement for all months.

distances, thus making the wind parameter to be known as the less correlated variable in space. This is much pronounced in rugged areas like Iran (Fig. 1a), where plain areas are separated by mountains and highlands. Moreover, every region may have local winds with limited areas of influence, which induces substantial differences among wind measurements of nearby stations. However, the relatively higher agreement found for summer months can be related to the less spatially variable wind speed throughout Iran due to the domination of stable synoptic patterns over whole the country in this season (Raziei et al., 2012a, 2012b; Zaitchik et al., 2007); the occurrence of extreme summer wind in eastern Iran is an exception. 
The accuracy of the interpolation of the variables is reasonably high and acceptable, particularly regarding to the $T_{\max }, T_{\min }, \mathrm{RH}$ and sunshine duration. The relatively higher estimation errors for wind speed were expected since it is a locally dependent variable and is substantially influenced by topography and regional advection as analysed in a previous study (Raziei and Pereira, 2013). The station networks of the present study (Fig. 1b) is relatively sparse, particularly in the central-eastern and southern parts of Iran, and contains severe elevation gradients (Fig. 1a) that are likely to cause large estimation errors for sparse and isolated stations through cross-validation procedure. In such an area as Iran, which is relatively large with diverse climates and topographic features, withholding a station from the networks through cross-validation procedure often forces the interpolator to have an estimation for isolated points based upon much apart locations; consequently, large estimation errors yield for sparse and isolated stations. This is also the case for the high elevation stations scattered in western and northern mountainous areas. Withholding such stations from the networks means that the estimating values for those points, based upon much lower elevation points, result in higher estimation errors. However, the cross-validation errors may exceed actual interpolation errors since the network is slightly degraded (to $n-1$ stations), making it more sparse locally, specifically when dealing with sparse and irregularly spaced networks of stations. Therefore, the real interpolation result would be more accurate and closer to the observations than that relative to the cross-validation outputs (Willmott and Mastuura, 1995).

Fig. 4 shows the spatial variability of the mean interpolation errors relative to each considered variable obtained from cross validation. In general, these error maps do not illustrate consistent
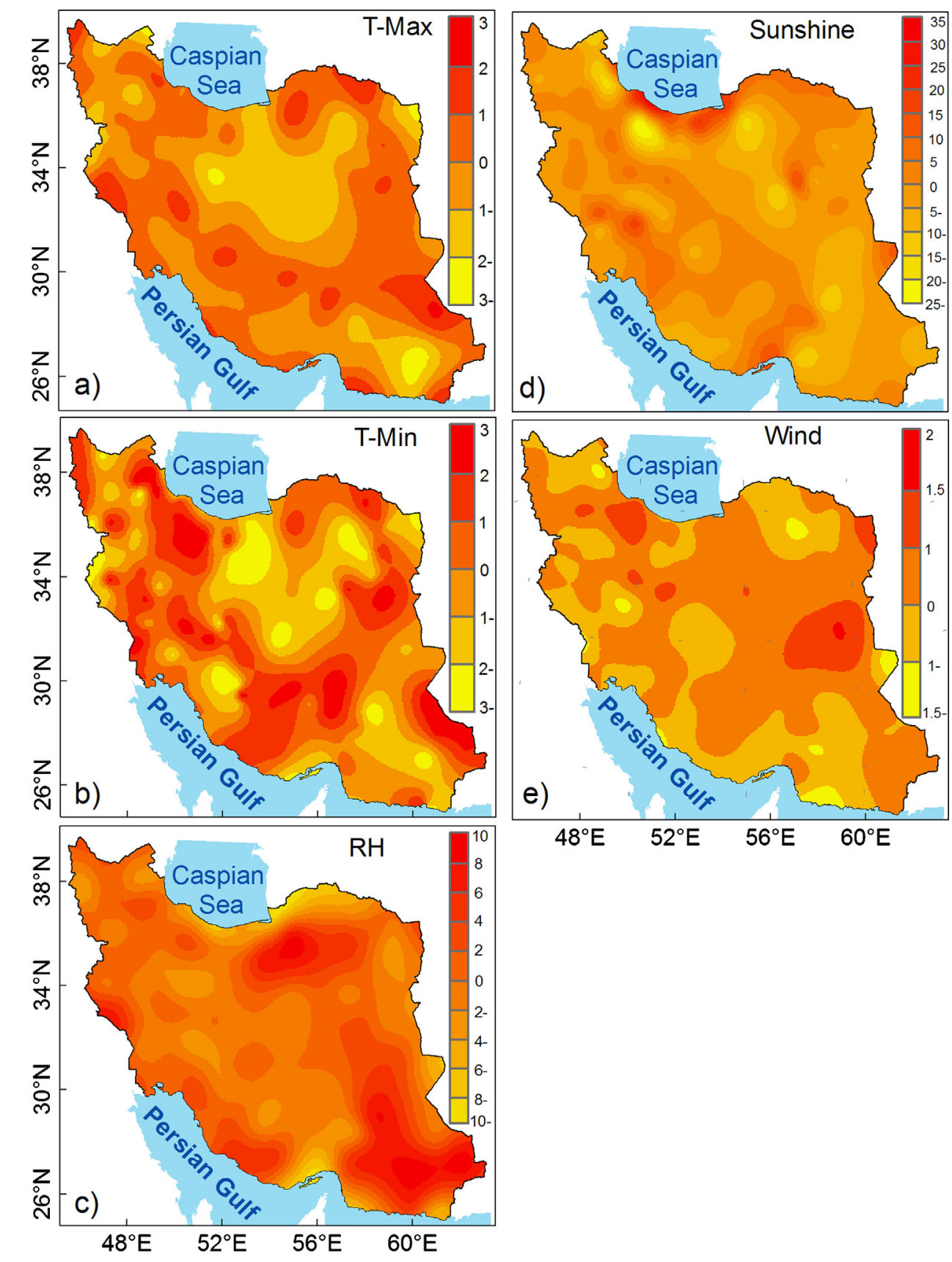

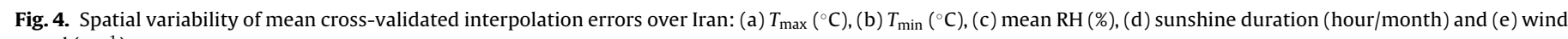
speed $\left(\mathrm{m}^{-1}\right)$. 
spatial patterns of errors but, contrarily, they indicate that the interpolation errors are randomly distributed over the country. The largest observed errors in the maps appear as isolated anomalies interspersed over the area. Most of the spot areas of high errors refer to isolated stations, particularly high elevation sites where some variables were overestimated/underestimated through cross-validation due to using data from surrounding stations with lower elevations. This is the case of overestimations of $T_{\min }$ and $T_{\max }$ in mountainous areas, since temperature is a topography dependent variable. Differently, the noticeable underestimations of $T_{\min }$ and $T_{\max }$ variables in Fig. 4a and b mostly correspond to isolated stations in areas of central-eastern Iran where the stations network is quite sparse and where advection may affect temperature. The observed spatial distribution of errors, particularly for the cases of sunshine duration, wind speed and RH (Figs. 4c-e) is likely to be influenced by the abrupt changes in climate features in short distances or to the artefacts-like of unique microclimates affecting specific stations, as well as to nonmeteorological peculiarities in the station observations as noted by Degaetano and Belcher (2007). Noticeable underestimation of RH (Fig. 4c) in the coastal areas of northern and southern Iran is due to the influence of neighbouring drier stations located a few kilometres away from the coastal stations. The noticeable overestimation of sunshine duration in the Caspian Sea region is likely related to the fact that the region is extremely narrow, therefore not existing enough stations in this area, thus involving stations of interior Iran in the interpolation procedure, that deviate the estimation results relative to observations in this area (Fig. $4 \mathrm{~d}$ ). The error map of wind
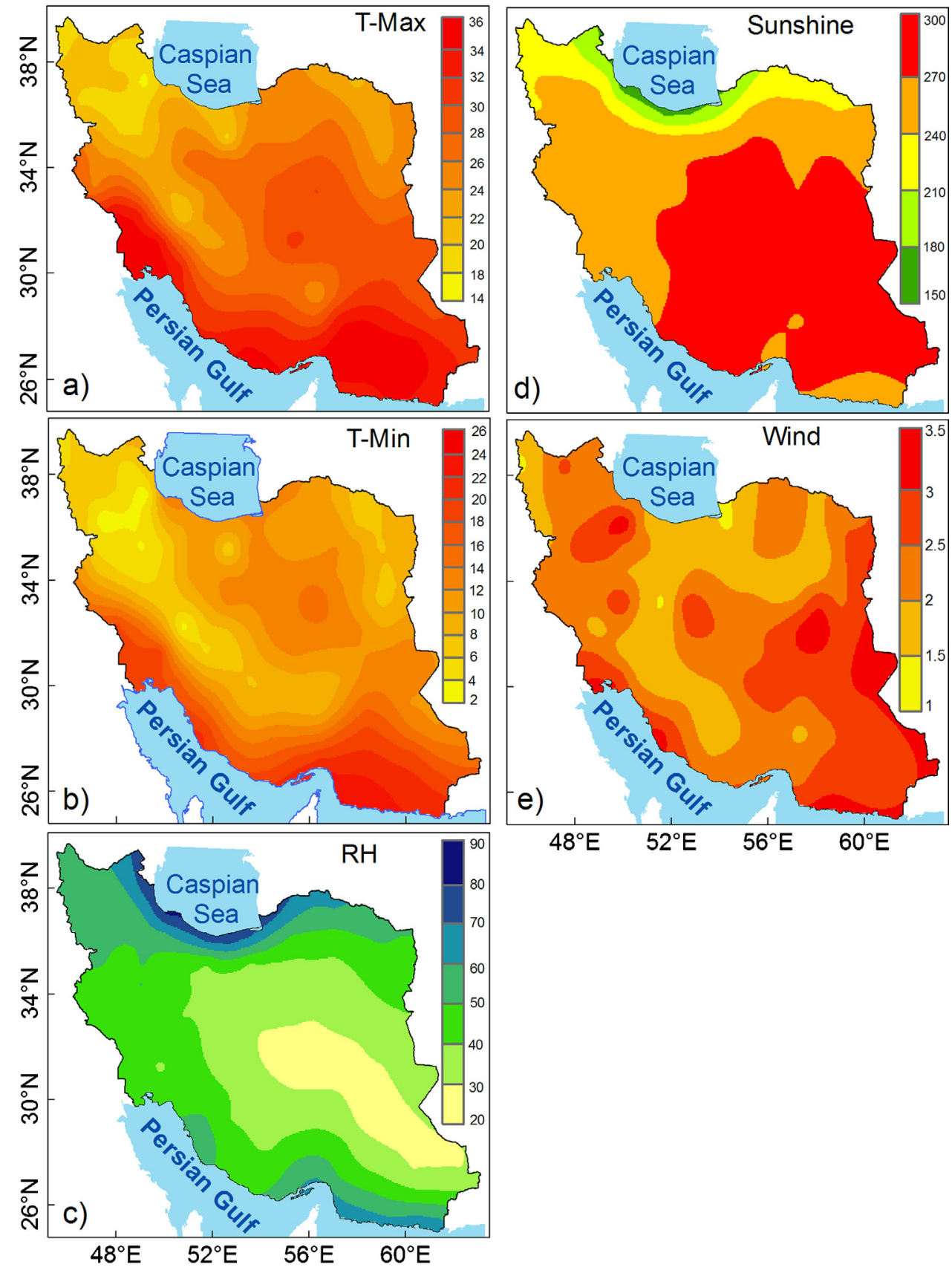

$48^{\circ} \mathrm{E}$

$52^{\circ} \mathrm{E}$

$56^{\circ} \mathrm{E} \quad 60^{\circ} \mathrm{E}$

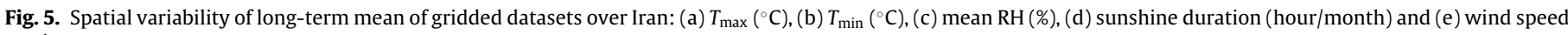
$\left(\mathrm{m}^{-1}\right)$. 
speed (Fig. 4e) shows similar characteristics which is expected as the wind speed is a locally dependent variable and substantially varies in space (New et al., 2002).

Fig. 5 shows spatial patterns of the long-term annual average of the gridded variables over Iran. The space variation of annual average of the gridded variables coincide well with the real spatial patterns of each variable in Iran (Alijani, 1997; Masoudian and Kaviani, 2007), i.e., reflecting the role played by topography and sea neighbourhood in spatial distribution of the variables. In Fig. 5a and $b$ the role of northwest-southeast oriented Zagros mountains (Fig. 1a) is well represented. In these figures, southern and central eastern Iran are well identified as regions with the highest temperature due to the lower latitude and/or altitude, as well as due to the stable subsidence of the dynamic high pressure system over the southern half of Iran in warm season, resulting in very hot and dry weather from April to September. The role of sea neighbourhood is also well illustrated in Fig. $5 c$, in identifying the highest mean relative humidity in the Caspian Sea region, in the north, and the coastal areas of Oman sea and Persian Gulf in the south. In Fig. 5c, the mountainous areas of western and northern Iran show annual mean relative humidity equal to $40-50 \%$, while central-eastern Iran where the desert areas of Dashte Kavir and Dashte Lut are located is identified as the driest area due to positioning in the lee side of the Zagros and Alborz mountains (Fig. 1a). Fig. 5d shows that the sunshine duration is mostly controlled by latitude and sea neighbourhood, but is also influenced by orography. Therefore, most parts of Iran in southern and central-eastern country are depicted as areas having annual mean monthly sunshine duration of 270-300 h, decreasing gradually to the north due to the additional effect of orography and vicinity of the sea that represent
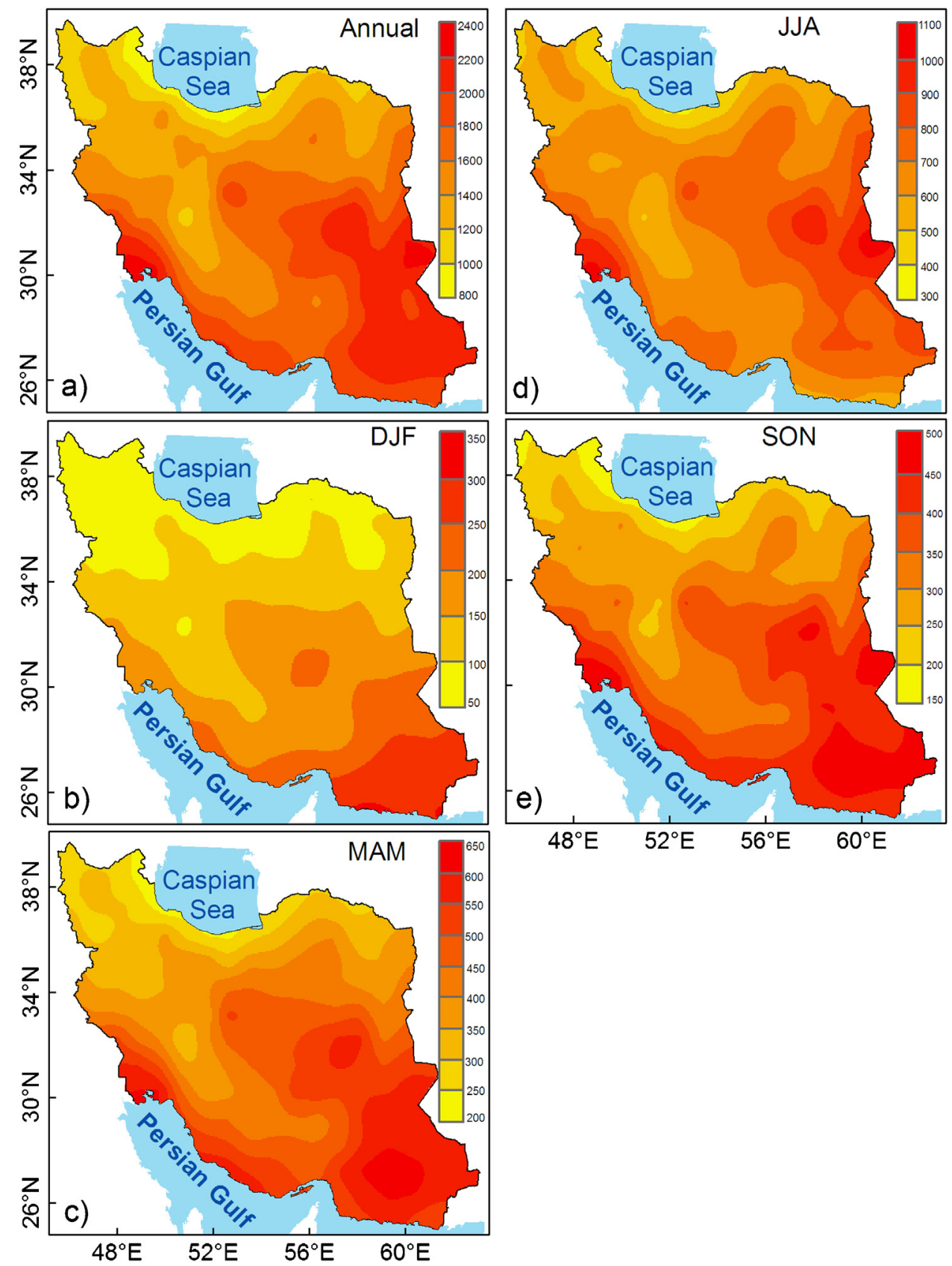

Fig. 6. Spatial variability of long-term mean annual and seasonal $\mathrm{ET}_{\mathrm{o}}$ over Iran using the gridded variables: (a) annual, (b) winter, (c) spring, (d) summer, and (e) autumn. 
an increase of relative humidity and cloudiness, therefore reducing sunshine duration. The spatial variability of wind speed in Iran is illustrated in Fig. 5e, showing the highest and the lowest values for eastern and central-northern Iran, respectively. The spatial patterns of the gridded results of the considered variables look much realistic and in agreements with literature (Alijani, 1997; Masoudian and Kaviani, 2007).

\subsection{Spatial pattern of $E T_{o}$}

Fig. 6a illustrates the spatial pattern of long-term mean annual

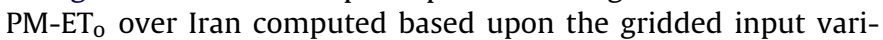
ables. The figure suggests a gradual increase of $\mathrm{ET}_{0}$ from north to South, with the lowest values over the northern humid and sub-humid climates of Iran and larger $\mathrm{ET}_{0}$ estimates for arid and hyper-arid climates in the southern and eastern country. The range of annual $\mathrm{ET}_{\mathrm{o}}$ varies from $800 \mathrm{~mm}$ in the humid coastal areas of southern Caspian Sea up to $2400 \mathrm{~mm}$ in hyper-arid desert areas of eastern Iran. The Caspian Sea area is characterized with $800-1000 \mathrm{~mm} \mathrm{ET}_{0}$, whereas the mountainous areas of northern and north-western Iran depict $\mathrm{ET}_{0}$ values between 1000 and $1400 \mathrm{~mm}$, increasing southward and eastward due to the decrease in latitude and/or altitude. The mountainous areas of southern part of Zagros and its western and eastern flanks, as well as the foothills of Alborz in mid-central Iran, exhibit $\mathrm{ET}_{0}$ between 1400 and $1800 \mathrm{~mm}$, while the $\mathrm{ET}_{\mathrm{o}}$ values for a vast area in central, southern and eastern Iran range from 1800 to $2400 \mathrm{~mm}$. The highest $\mathrm{ET}_{0}$, with 2200 to $2400 \mathrm{~mm}$, occurs in south-western and eastern Iran. The high $\mathrm{ET}_{\mathrm{o}}$ in south-western Iran is related to temperature, the highest observed in the country, and relatively dominant heat advection and extreme wind speed in summer. Differently, in eastern Iran, it likely relates to the very high wind speed (Fig. 5e), dryness and heat advection; a very low annual mean relative humidity occurs there $(<40 \%$, Fig. $5 c)$, which even reduces to $<25 \%$ in summer, when the region is exposed to extreme wind speed.

Trends in $\mathrm{ET}_{0}$ have been reported by Dinpashoh et al. (2011) for different geographic regions of Iran. Such trends are expected when significant changes in any variable involved in $\mathrm{ET}_{0}$ estimation would occur; using the gridded data developed may better supporting to understand the respective variation patterns.

The spatial pattern of PM-ET ${ }_{0}$ over Iran produced herein using the gridded datasets as input variables is comparable to that presented by Raziei and Pereira (2013) and Dinpashoh (2006), though the number of used stations in those works is far less than for the present study and the considered data periods are different. However, the spatial pattern of $\mathrm{PM}^{-\mathrm{ET}_{0}}$ in the present study is much smoother and consistent than those of the previous works (Raziei and Pereira, 2013; Dinpashoh, 2006) due to using much denser stations for gridding the variables, particularly those relative to sunshine duration, relative humidity and wind speed, that commonly suffer from substantial missing values.

Fig. 6b-e shows the spatial patterns of seasonal PM-ET ${ }_{0}$ over Iran, depicting relatively the same configuration as for the mean annual pattern shown in Fig. 6a. Fig. 6b suggests that the spatial

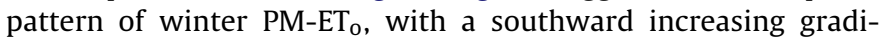
ent, is largely controlled by latitude, that can be related to the dominance of large-scale atmospheric synoptic patterns in this season (Raziei et al., 2012a, 2012b; Zaitchik et al., 2007). Contrarily, Fig. $6 c$ and 6e better reflect the role of topography in delineating the spatial variability of spring and autumn PM-ET, i.e., showing relatively lower $\mathrm{ET}_{0}$ over the mountain ranges of Zagros and Alborz in western and northern Iran, respectively. As in Fig. $6 \mathrm{~b}$ the role of topography in western Iran is relatively less evident in Fig. 6d; this likely refers to the fact that
Table 3

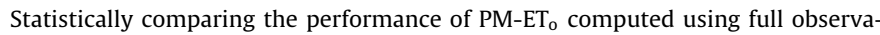
tional datasets in some selected stations distributed through Iran (Fig. 1b) and those of using gridded variables averaged over the four grids surrounding a given station.

\begin{tabular}{lllll}
\hline Stations & $R$ & RMSE $\left(\mathrm{mmd}^{-1}\right)$ & EF & $d_{\mathrm{IA}}$ \\
\hline Tabriz & 0.99 & 0.54 & 0.95 & 0.99 \\
Zanjan & 0.99 & 0.28 & 0.98 & 1.00 \\
Hamedan & 0.99 & 0.47 & 0.96 & 0.99 \\
Kermanshah & 0.99 & 0.27 & 0.99 & 1.00 \\
Ahwaz & 0.99 & 0.40 & 0.98 & 1.00 \\
Shiraz & 0.99 & 0.41 & 0.96 & 0.99 \\
Tehran & 1.00 & 0.45 & 0.96 & 0.99 \\
Yazd & 0.99 & 0.48 & 0.96 & 0.99 \\
Kerman & 0.99 & 0.27 & 0.99 & 1.00 \\
Isfahan & 0.99 & 0.24 & 0.99 & 1.00 \\
Mashhad & 0.99 & 0.40 & 0.97 & 0.99 \\
Shahroud & 0.99 & 0.56 & 0.93 & 0.98 \\
Babolsar & 1.00 & 0.13 & 0.99 & 1.00 \\
Rasht & 1.00 & 0.22 & 0.97 & 0.99 \\
Iranshahr & 0.98 & 0.63 & 0.94 & 0.98 \\
Zahedan & 0.99 & 0.47 & 0.95 & 0.99 \\
Tabas & 0.99 & 0.44 & 0.97 & 0.99 \\
Bandar Abas & 0.99 & 0.30 & 0.97 & 0.99 \\
Birjand & 0.99 & 0.94 & 0.85 & 0.97 \\
Zabol & 0.98 & 2.15 & 0.80 & 0.95 \\
\hline
\end{tabular}

the dynamic high pressure system that relatively dominates the whole country in summer acts as a large scale driver in control-

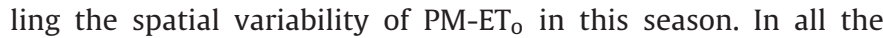
seasons the lowest $\mathrm{ET}_{0}$ is observed in the Caspian sea area and the highest values correspond to south-eastern and south-western Iran.

\subsection{Re-evaluation of grid based PM-ETo}

The adequacy of the gridded variables when used for PM-ET estimation across Iran was assessed through a set of goodness of fit indicators (Table 3) applied to some selected stations representative of all climatic and geographic features of Iran (Fig. 1b). The statistics indicate that the $\mathrm{PM}-\mathrm{ET}_{0}$ computed using gridded variables well fitted the PM-ET ${ }_{0}$ computed using observed full weather variables at selected stations, which is supported by a correlation coefficient $(R)$ higher than 0.98 and the EF and $d_{\mathrm{IA}}$ statistics higher than 0.94. Except for Zabol and Birjand in the arid and windy eastern Iran, the RMSE is lower than $0.65 \mathrm{~mm} \mathrm{~d}^{-1}$ in all stations, giving a good indication of the accuracy of the gridding process in estimating values of each variable at all locations which appeared in the resultant $\mathrm{PM}-\mathrm{ET}_{\mathrm{O}}$. The relatively lower agreement in Zabol and Birjand stations, as indicated by higher RMSE and lower EF indicators, can be partially related to the sparser station network in eastern Iran used for gridding the variables and to the influence of the smoothed gridded wind variable for the area, which is relatively lower than the actual observed wind speed at these stations, particularly for Zabol, where its wind speed is far higher than those of the surrounding but distant stations (Raziei and Pereira, 2013).

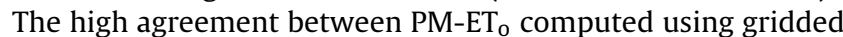
and observation variables (Table 3 ) is an indication of the adequacy of the gridding processes, which can serve as a useful tool to provide fine spatial resolution datasets of the required variables

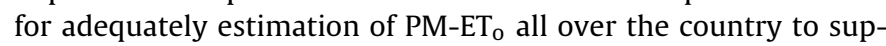
port a wide range of agricultural and irrigation management, as well as water resources applications at catchment and watershed scale. This is particularly important for areas where the stations

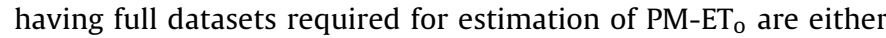
very sparse or suffer from substantial missing values, particularly considering sunshine duration and wind speed variables, which most often face data gaps. 

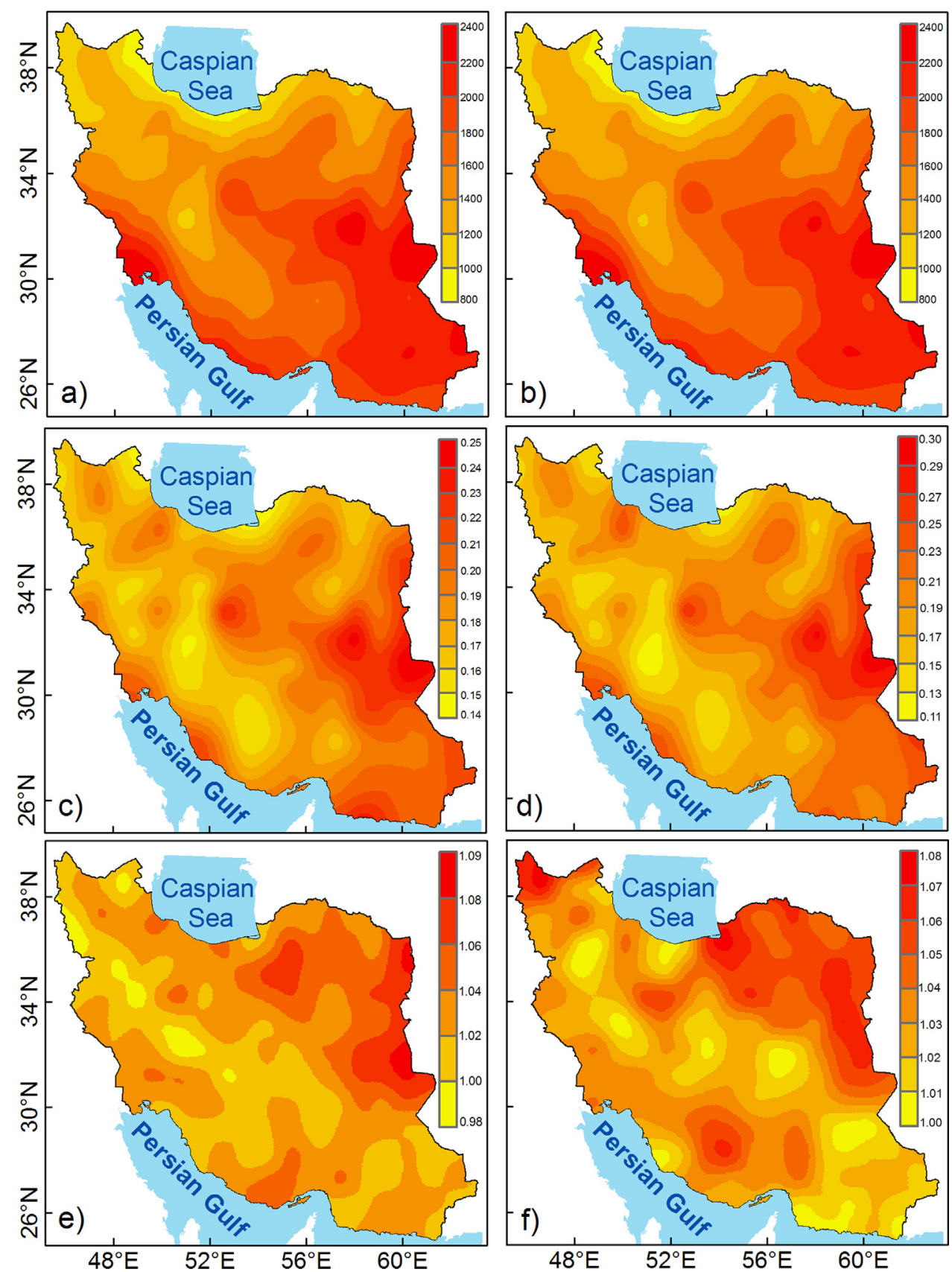

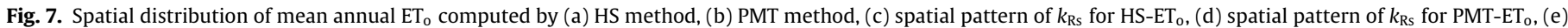
spatial pattern of $\mathrm{HS} /{\mathrm{PM}-\mathrm{ET}_{\mathrm{o}} \text { ratio and (f) spatial pattern of PMT/PM-ET }}_{\mathrm{o}}$ ratio over Iran.

\subsection{Estimation of $E T_{o}$ with temperature methods}

The satisfactory result achieved using the gridded variables

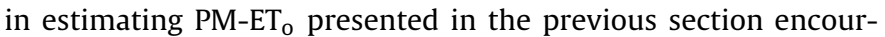
aged us to estimate $\mathrm{ET}_{\mathrm{o}}$ with temperature methods using only the gridded variables of $T_{\min }$ and $T_{\max }$. Fig. $7 \mathrm{a}$ and $\mathrm{b}$ show spatial patterns of long-term mean annual HS-ET ${ }_{0}$ and PMT-ET $_{0}$ over Iran, respectively, computed using the gridded variables of $T_{\min }$ and $T_{\max }$. Spatial variability of $\mathrm{HS} \mathrm{ET}_{\mathrm{o}}$ and $\mathrm{PMT}_{\mathrm{ET}}$ are iden-

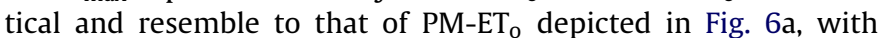
the same magnitude of $\mathrm{ET}_{\mathrm{o}}$ all over the country, suggesting that the HS and PMT methods can be used as alternatives to full data PM method (Eq. (3)) to appropriately estimate $\mathrm{ET}_{\mathrm{o}}$ all over the country using only $T_{\max }$ and $T_{\min }$. Spatial patterns of the appropriate $k_{\mathrm{Rs}}$ used for estimation of $\mathrm{HS}-\mathrm{ET}_{\mathrm{o}}$ and $\mathrm{PMT}-\mathrm{ET}_{\mathrm{o}}$ through the country, shown in Fig. 7c and d respectively, are very similar and consistent, indicating that the appropriate $k_{\mathrm{Rs}}$ used for estimation of $\mathrm{ET}_{\mathrm{o}}$ by both methods strongly co-vary across the country. For both methods, the lowest $k_{\mathrm{Rs}}$ is observed in the Caspian Sea region and in the mountainous areas of western Iran, while the highest $k_{\mathrm{Rs}}$ is observed in the hyper-arid region of eastern Iran.

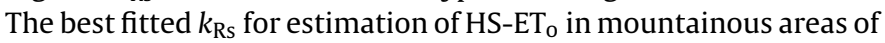
western and northern Iran characterized with semi-arid to humid climates (see Fig. 1d) ranges from 0.14 to 0.18 , while it varies between 0.19 and 0.25 in arid to hyper-arid climates of centraleastern and south-western Iran (Fig. 7c). Spatial pattern of the appropriate $k_{\mathrm{Rs}}$ used for estimation PMT-ET $\mathrm{PT}_{\mathrm{o}}$ is identical to that of HS-ET ${ }_{0}$; however, differently, the best fitted $k_{\mathrm{Rs}}$ is slightly lower 
Table 4

Statistical indicators comparing the performance of HS and PMT methods with PM-ET ${ }_{0}$ estimates for the climatic zones depicted in Fig. 1d.

\begin{tabular}{|c|c|c|c|c|c|c|c|c|}
\hline \multirow[t]{2}{*}{ Climatic zone } & \multicolumn{4}{|l|}{ HS vs. PM-ETo } & \multicolumn{4}{|l|}{ PMT vs. PM-ET } \\
\hline & $\operatorname{RMSE}\left(\mathrm{mm} \mathrm{d}^{-1}\right)$ & $R^{2}$ & $d_{\mathrm{IA}}$ & $\mathrm{EF}$ & $\operatorname{RMSE}\left(\mathrm{mm} \mathrm{d}^{-1}\right)$ & $R^{2}$ & $d_{\mathrm{IA}}$ & $\mathrm{EF}$ \\
\hline Hyper-arid & 0.66 & 0.94 & 0.98 & 0.93 & 0.62 & 0.94 & 0.98 & 0.94 \\
\hline Arid & 0.59 & 0.95 & 0.98 & 0.94 & 0.58 & 0.95 & 0.98 & 0.94 \\
\hline Semi-arid & 0.41 & 0.97 & 0.99 & 0.97 & 0.45 & 0.97 & 0.99 & 0.96 \\
\hline Dry-sub humid & 0.35 & 0.98 & 0.99 & 0.97 & 0.40 & 0.97 & 0.99 & 0.96 \\
\hline Moist-sub-humid & 0.26 & 0.98 & 0.99 & 0.98 & 0.32 & 0.96 & 0.99 & 0.96 \\
\hline Humid & 0.29 & 0.98 & 0.99 & 0.95 & 0.25 & 0.97 & 0.99 & 0.97 \\
\hline
\end{tabular}

than that of $\mathrm{HS}_{-\mathrm{ET}_{\mathrm{o}}}$ in western Iran, where it ranges between 0.11 and 0.17 , and is reasonably higher in arid and hyper-arid areas of eastern Iran, where the best fitted $k_{\mathrm{Rs}}$ varies between 0.25 and 0.29 (Fig. 7d). The result suggests that the difference between the best fitted $k_{\mathrm{Rs}}$ for HS and PMT methods is negligible in most parts of Iran, with the exception of cold and humid areas of western Iran and the very dry and windy areas of eastern country where the difference is reasonably higher. The present results are in agreement with the previous study for Iran by Raziei and Pereira (2013) using sparse and irregularly spaced network of stations.

The annual $\mathrm{ET}_{0}$ estimates by HS and PMT methods were compared to the $P M-E_{0}$ estimates for all the considered grid points shown in Fig. 1b by means of the ratio of HS (PMT) to PM-ET

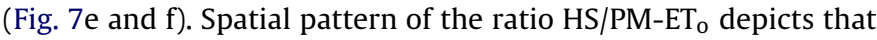

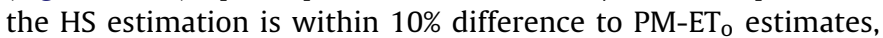
i.e., HS/PM-ET o $_{0}$ ranged from 0.98 to 1.09 through the country, thus

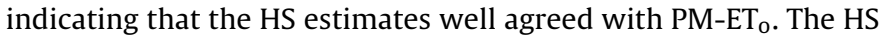
estimates for majority portion of the country in western, central

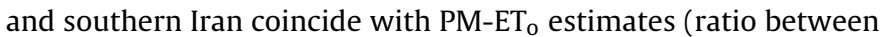
0.98 and 1.04), whereas in eastern and north-eastern Iran the HS slightly over-estimated $\mathrm{ET}_{\mathrm{o}}$ (ratio between 1.04 and 1.09; Fig. 7e). Fig. $7 \mathrm{f}$ depicts spatial distribution of the ratio of PMT estimates to

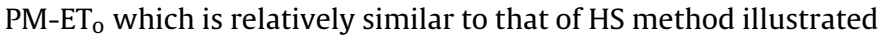
in Fig. 7e. Except eastern, north-eastern and a small area in northwestern Iran which shows a slight overestimation (ratio between 1.04 and 1.08), the PMT estimation coincides well with PM-ET, particularly for south-eastern and central-western Iran.

Table 4 illustrates statistical indicators, averaged for each climatic zone identified in Fig. 1d, used to statistically assess the performances of HS and PMT methods with respect to PM-ET The quite high values of the average of $\mathrm{EF}$ and $d_{\mathrm{IA}}$ indicators as well as the low values of RMSE suggest that both the HS and PMT methods are accurate and worthwhile approaches for $\mathrm{ET}_{0}$ estimation in all climatic regions of Iran. The table suggests that both methods have relatively similar performance in all climate zones. The statistics are similar to those computed by Raziei and Pereira (2013) using observational datasets. However, the RMSE values of the present study are generally smaller than for the former one thus indicating that using gridded datasets to estimate monthly $\mathrm{ET}_{0}$ with temperature methods provides accurate estimations all over the country.

The HS method performs slightly better than PMT in semi-arid, dry-sub-humid and moist-sub-humid climates as indicated by reasonably lower RMSE and higher EF and $d_{\mathrm{IA}}$ statistics for the HS method. However, the PMT shows slightly better performance in arid, hyper-arid and humid climates considering its lower RMSE values and higher $E F$ and $d_{\mathrm{IA}}$ with respect to HS method. Very likely, better performance of PMT in these regions is related to the adjustment of minimum temperature which has been already proved by Raziei and Pereira (2013) for the same regions.

Fig. 8 illustrates the spatial distribution of the coefficient of determination $\left(R^{2}\right)$ relating $\mathrm{HS}-\mathrm{ET}_{0}$ and $\mathrm{PMT}^{-\mathrm{ET}_{0}}$ with $\mathrm{PM}-\mathrm{ET}_{0}$ estimates through Iran. Results suggest that both methods perform quite well all over the country with relatively identical spatial variability and $R^{2}$ values. The $R^{2}$ value for both methods is higher than 0.95 all over the country except for south-eastern Iran, with relatively lower $R^{2}$ values, ranging from 0.90 to 0.95 . Results indicate that the HS and PMT methods explain more than 95\% of the vari-

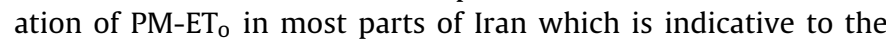
accurate estimation by both methods. Better performance of PMT method in hyper-arid region of south-eastern Iran is evident in Fig. 8b, where the PMT method shows slightly higher $\mathrm{R}^{2}$ values with respect to HS method (Fig. 8a) that can be related to the correction in minimum temperature for aridity when using PMT. The RMSE, EF and $d_{\mathrm{IA}}$ statistics show similar spatial distribution over the country (not shown).

According to Raziei and Pereira (2013) the occurrence of extreme summer winds in eastern arid and hyper-arid areas of

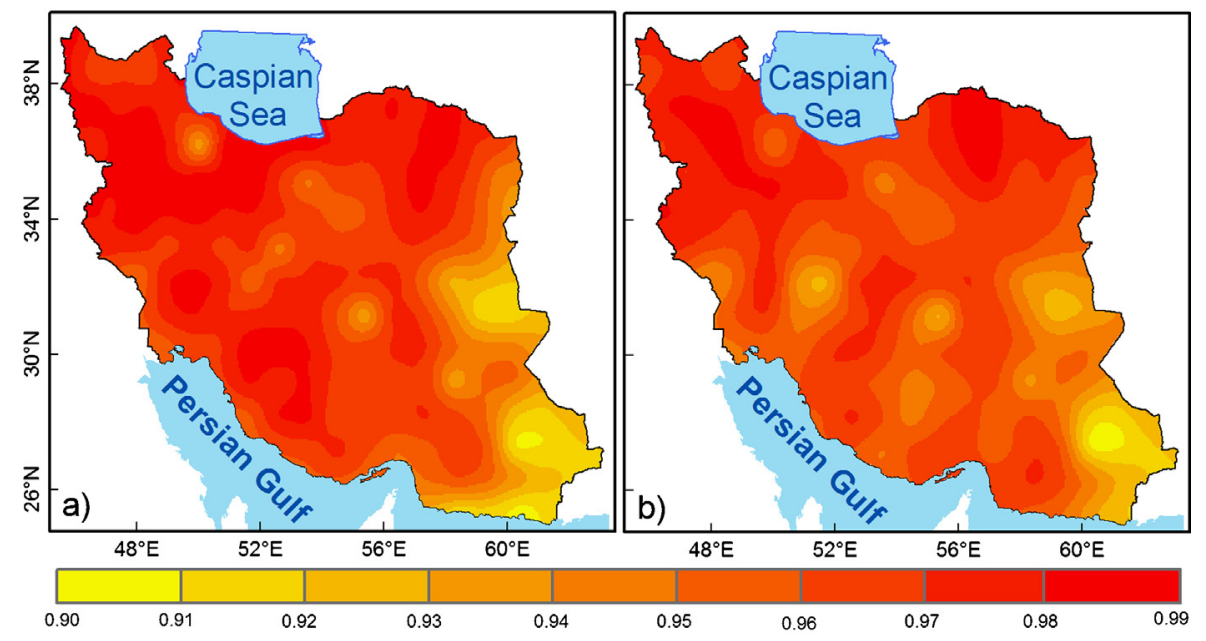

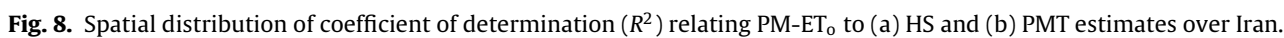


Iran resulted in extreme PM-ET $\mathrm{E}_{\mathrm{O}}$ that are underestimated by both HS and PMT methods. Thus, to eliminate underestimations, large $k_{\mathrm{Rs}}$ values were identified, which is in agreement with the results obtained with observation data (Raziei and Pereira, 2013).

In arid and hyper-arid climates, advection often impacts local equilibrium saturation deficit by transporting excess heat during windy days, resulting in enhanced ET rate (Brakke et al., 1978, Malek, 1987). Surface heating is a dominant climatic feature in Iran during warm season (April-October) due to the existence of a strong air subsidence, providing excess heat energy for advection of sensible heat flux (Zaitchik et al., 2007) mainly in southern (Malek, 1987) and eastern Iran (Daneshkar Arasteh and Tajrishy, 2008).

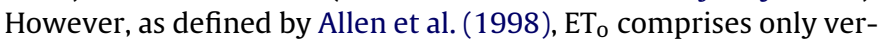
tical fluxes, not including advection effects; thus crop coefficients used to compute crop evapotranspiration from $\mathrm{ET}_{\mathrm{o}}$ need to be adjusted to consider advection (Allen et al., 1998). However, the FAO-PM equation is supposed to perform well even when advection occurs (Berengena and Gavilán, 2005; Allen et al., 2006). Nevertheless, the advective energy carried by extreme summer winds passing over dry and hot deserts may also be considered as an additional factor responsible for deviating the estimate by HS and PMT from PM-ET and consequently leading to fit higher $k_{\mathrm{Rs}}$ values for regions where advection occurs.

\section{Discussion and conclusions}

Aiming at providing high resolution spatial surfaces of $\mathrm{ET}_{\mathrm{O}}$ estimates for Iran, monthly averages of maximum and minimum temperature, mean relative humidity, sunshine duration and wind speed at $2 \mathrm{~m}$ height, relative to 148 Iranian weather stations distributed over the country were utilized for interpolation and gridding the variables. The results suggested that the accuracy of the interpolation outputs is reasonably high, particularly regarding to the $T_{\max }, T_{\min }, \mathrm{RH}$ and sunshine duration. Higher estimation errors were found for wind speed because it is a locally dependent variable and substantially influenced by topography. Results indi-

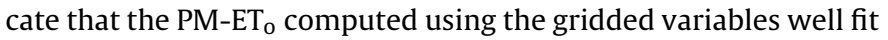

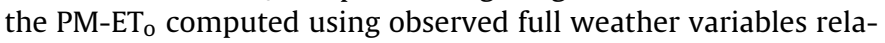
tive to the selected stations representative of all Iranian climates. This high agreement is an indication to the adequacy of the gridding processes, which can serve as a useful tool to provide fine spatial resolution datasets of the required variables for adequately

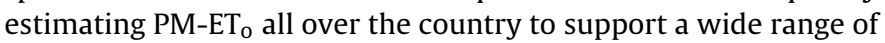
applications. This is particularly important for areas where weather stations are either very sparse or suffer from substantial missing values, particularly relative to sunshine duration and wind speed variables.

The spatial pattern of long-term mean annual PM-ET $_{0}$ over Iran computed with the gridded variables suggests a gradual increase of $\mathrm{ET}_{\mathrm{o}}$ from north to south, with the lowest values over northern humid and sub-humid climates of Iran and larger estimates in arid and hyper-arid climates of south-eastern country. The spatial

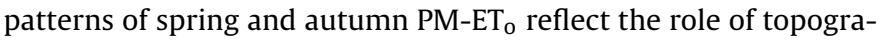

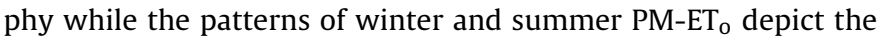
dominance of large-scale atmospheric synoptic patterns.

The estimated $\mathrm{ET}_{\mathrm{o}}$ with temperature methods using only grid-

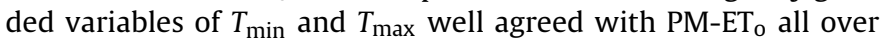
the country. Spatial patterns of long-term mean annual $\mathrm{HS}_{\mathrm{S}} \mathrm{ET}_{\mathrm{O}}$ and $\mathrm{PMT}_{-\mathrm{ET}_{0}}$ computed with the gridded variables are identical and resemble to that of $\mathrm{PM}-\mathrm{ET}_{0}$. This suggests that the HS and PMT methods can be used when only limited variables are available. Spatial patterns of the appropriate radiation coefficient $k_{\mathrm{Rs}}$ used with the HS and PMT methods are also very similar and consistent throughout Iran, indicating that the appropriate $k_{\mathrm{Rs}}$ show strong co-variability across the country. For both methods, lower
$k_{\mathrm{Rs}}$ are observed in the Caspian Sea region and mountainous areas of western Iran, while higher $k_{\mathrm{Rs}}$ are observed in hyper-arid regions of eastern Iran. It could be concluded that the $k_{\mathrm{Rs}}$ increases with sky clearness as governed by latitude and altitude and decreases for cloudy locations with lower temperature. $k_{\mathrm{Rs}}$ also increases for windy locations as is the case in eastern Iran.

Spatial patterns of the ratio of annual $\mathrm{ET}_{\mathrm{O}}$ estimated by $\mathrm{HS}$ and PMT methods to the PM-ET $\mathrm{P}_{0}$ estimates depicted that the HS and

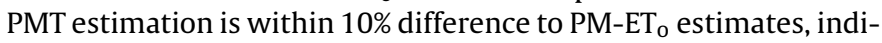

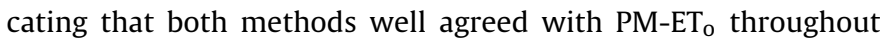
Iran. Statistics suggest that the HS method performs slightly better in semi-arid, dry-sub-humid and moist-sub-humid climates, whereas PMT slightly better performed in arid, hyper-arid and humid climates. Very likely, the good performance of PMT is related to the adjustment of minimum temperature when estimating the dew point temperature. Further studies suggested by the achieved results include assessing the impact of heat advection on ET estimation with temperature data only, as well as further analysing the time and space variability of wind speed through Iran. An evaluation of the adopted $\mathrm{ET}_{0}$ methodologies when using daily datasets is also required. A further analysis of $\mathrm{ET}_{\mathrm{o}}$ trends in relation to the computational methods used is also desirable.

The study was successful in providing means for reasonably accurate $\mathrm{ET}_{\mathrm{o}}$ estimates for Iran at a fine spatial resolution that can be used for various agricultural and water resources management purposes at regional to watershed levels. Therefore, it can also be concluded that these methodologies may be used in other areas in order to develop high resolution gridded $\mathrm{ET}_{0}$ estimates for a range of spatial scales.

\section{References}

Adler, R.F., Susskind, J., Huffman, G.J., Bolvin, D., Nelkin, E., Chang, A., Ferraro, R., Gruber, A., Xie, P.P., Janowiak, J., Rudolf, B., Schneider, U., Curtis, S., Arkin, P., 2003. The version 2 global precipitation climatology project (GPCP) monthly precipitation analysis (1979-present). Journal of Hydrometeorology 4, 1147-1167.

Alijani, B., 1997. The Climate of Iran. Payame Nour Publication Series, Teheran, Iran, pp. 221 (in Persian).

Allen, R.G., Pereira, L.S., Raes, D., Smith, M., 1998. Crop Evapotranspiration. Guidelines for Computing Crop Water Requirements. FAO Irrig. Drain. Pap. 56. FAO, Rome, pp. 300.

Allen, R.G., Pruitt, W.O., Wright, J.L., Howell, T.A., Ventura, F., Snyder, R., Itenfisu, D., Steduto, P., Berengena, J., Baselga, J., Smith, M., Pereira, L.S., Raes, D., Perrier, A., Alves, I., Walter, I., Elliott, R., 2006. A recommendation on standardized surface resistance for hourly calculation of reference $\mathrm{ET}_{0}$ by the FAO 56 Penman-Monteith method. Agricultural Water Management 81, $1-22$.

Angström, A., 1924. Solar and terrestrial radiation. Quaterly Journal of Royal Meteorological Society 50, 121-125.

Belo-Pereira, M., Dutra, E., Viterbo, P., 2011. Evaluation of global precipitation data sets over the Iberian Peninsula. Journal of Geophysical Research 116, D20101, http://dx.doi.org/10.1029/2010JD015481.

Berengena, J., Gavilán, P., 2005. Reference evapotranspiration estimation in a highly advective semiarid environment. Journal of Irrigation and Drainage Engineering 131 (2), 147-163.

Biau, G., Zorita, E., von Storch, H., Wackernagel, H., 1999. Estimation of precipitation by kriging in the EOF space of the sea level pressure field. Journal of Climate 12, 1070-1085.

Brakke, T.W., Verma, S.B., Rosenberg, N.J., 1978. Local and regional components of sensible heat advection. Journal of Applied Meteorology 17, 935-963.

Cai, J., Liu, Y., Xu, D., Paredes, P., Pereira, L.S., 2009. Simulation of the soil water balance of wheat using daily weather forecast messages to estimate the reference evapotranspiration. Hydrology and Earth System Sciences 13, 1045-1059.

Daly, C., Gibson, W.P., Taylor, G.H., Johnson, G.L., Pasteris, P., 2002. A knowledgebased approach to the statistical mapping of climate. Climate Research 22, 99-113.

Daneshkar Arasteh, P., Tajrishy, M., 2008. Calibration Pristley-Taylor model to estimate open water evaporaton under regional advection using volume balance method - case study: Chahnimeh reservoir, Iran. Journal of Applied Sciences 8 (22), 4097-4104.

Degaetano, A.T., Belcher, B.N., 2007. Spatial interpolation of daily maximum and minimum air temperature based on meteorological model analyses and independent observations. Journal of Applied Meteorology and Climatology 46, 1981-1992.

Dinpashoh, Y., 2006. Study of reference crop evapotranspiration in I.R. of Iran. Agricultural Water Management 84, 123-129. 
Dinpashoh, Y., Jhajharia, D., Fakheri-Fard, A., Singh, V.P., Kahya, E., 2011. Trends in reference evapotranspiration over Iran. Journal of Hydrology 399, 422-433.

Dirks, K.N., Hay, J.E., Stow, C.D., Harris, D., 1998. High-resolution studies of rainfall on Norfolk Island, Part II: Interpolation of rainfall data. Journal of Hydrology 208 (3-4), 187-193.

Gong, L., Xu, C.Y., Chen, D., Halldin, S., Chen, Y.D., 2006. Sensitivity of the Penman-Monteith reference evapotranspiration to key climatic variables in the Changjiang (Yangtze River) basin. Journal of Hydrology 329, 620-629.

Haylock, M.R., Hofstra, N., Klein-Tank, A.M.G., Klok, E.J., Jones, P.D., New, M., 2008. A European daily high-resolution gridded data set of surface temperature and precipitation for 1950-2006. Journal of Geophysical Research 113, http://dx.doi.org/10.1029/2008JD010201, D20, 119.

Herrera, S., Gutiérrez, J.M., Ancell, R., Pons, M.R., Frías, M.D., Fernández, J., 2012. Development and analysis of a 50-year high-resolution daily gridded precipitation dataset over Spain (Spain02). International Journal of Climatology 32 74-85.

Hijmans, R., Cameron, S., Parra, J., Jones, P., Jarvis, A., 2005. Very high resolution interpolated climate surfaces for global land areas. International Journal of Climatology 25, 1965-1978.

Hofstra, N., Haylock, M., New, M., Jones, P., Frei, C., 2008. The comparison of six methods for the interpolation of daily European climate data. Journal of Geophysical Research 113, http://dx.doi.org/10.1029/2008JD010100, D21 110.

Holdaway, M.R., 1996. Spatial modelling and interpolation of monthly temperature using Kriging. Climate Research 6, 215-225.

Hutchinson, M.F., 1995. Interpolating mean rainfall using thin plate smoothing splines. International Journal of Geographical Information Systems 9 (4), 385-403.

Jones, P.D., Raper, S.C.B., Bradley, R.S., Diaz, H.F.P., Kelly, M., Wigley, T.M.L., 1986 Northern Hemisphere surface air temperature variations: 1851-1984. Journal of Climate and Applied Meteorology 25, 161-179.

Journel, A.G., Huijbregts, C.J., 1978. Mining Geostatistics. Academic Press, London, pp. 600.

Laslett, G.M., 1994. Kriging and splines: an empirical comparison of their predictive performance in some applications. Journal of American Statistical Association 89 (426), 391-400.

Liebmann, B., Allured, D., 2005. Daily precipitation grids for South America. Bulletin of the American Meteorological Society 86, 1567-1570.

Malek, E., 1987. Comparison of alternative methods for estimating $\mathrm{ET}_{\mathrm{p}}$ and evaluation of advection in the Bajgah area, Iran. Agricultural and Forest Meteorology 39, 185-192.

Masoudian, S.A., Kaviani, M.R., 2007. The Climate of Iran. Isfahan University Press, Isfahan, Iran, pp. 179 (in Persian).

Matheron, G., 1971. The theory of regionalized variables and its applications. Les Cahiers du Centre de Morphologie Mathématique, No_5. Fontainebleau, Ecole Nationale Supérieure des Mines de Paris.

Maurer, E.P., Wood, A.W., Adam, J.C., Lettenmaier, D.P., Nijssen, B., 2002. A long-term hydrologically based dataset of land surface fluxes and states for the conterminous United States. Journal of Climate 15 (22), 3237-3251.

Moriasi, D.N., Arnold, J.G., Van Liew, M.W., Bingner, R.L., Harmel, R.D., Veith, T.L. 2007. Model evaluation guidelines for systematic quantification of accuracy in watershed simulations. Transaction on ASABE 50 (3), 885-900.

Nandagiri, L., Kovoor, G.M., 2005. Sensitivity of the Food and Agriculture Organization Penman-Monteith evapotranspiration estimates to alternative procedures for estimation of parameters. Journal of Irrigation and Drainage Engineering 131 (3), 238-248.

Nash, J.E., Sutcliffe, J.V., 1970. River flow forecasting through conceptual models: Part 1. A discussion of principles. Journal of Hydrology 10 (3), 282-290.

New, M., Hulme, M., Jones, P., 1999. Representing twentieth-century space-time climate varibility. Part I: development of a 1961-90 mean monthly terrestial climatology. Journal of Climate 12,829-856.

New, M., Lister, D., Hulme, M., Makin, I., 2002. A high-resolution data set of surface climate over global land areas. Climate Research 21, 1-25.
Pereira, L.S., Perrier, A., Allen, R.G., Alves, I., 1999. Evapotranspiration: review of concepts and future trends. Journal of Irrigation and Drainage Engineering 125 (2), 45-51.

Pereira, L.S., Rosa, R.D., Paulo, A.A. 2007. Testing a modification of the Palmer drought severity index for Mediterranean environments. In: Rossi, G., Vega, T. Bonaccorso, B. (Eds.), Methods and Tools for Drought Analysis and Management. Springer, Dordrecht, pp. 149-167.

Perry, M., Hollis, D., 2005. The generation of monthly gridded datasets for a range of climatic variables over the UK. International Journal of Climatology 25 (8), 1041-1054.

Philips, D.L., Marks, D.G., 1996. Spatial uncertainity analysis: propagation of interpolation errors in spatially distributed models. Journal of Ecological Modeling 91, 213-219.

Popova, Z., Kercheva, M., Pereira, L.S., 2006. Validation of the FAO methodology for computing $\mathrm{ET}_{0}$ with missing climatic data. Application to South Bulgaria. Journal of Irrigation and Drainage 55 (2), 201-215.

Raziei, T., Pereira, L.S., 2013. Estimation of $\mathrm{ET}_{0}$ with Hargreaves-Samani and FAOPM temperature methods for a wide range of climates in Iran. Agricultural Water Management 121, 1-18.

Raziei, T., Bordi, I., Santos, J.A., Mofidi, A., 2012a. Atmospheric circulation types and winter daily precipitation in Iran. International Journal of Climatology, http://dx.doi.org/10.1002/joc.3596.

Raziei, T., Mofidi, A., Santos, J.A., Bordi, I., 2012b. Spatial patterns and regimes of daily precipitation in Iran in relation to large-scale atmospheric circulation. International Journal of Climatology 32,1226-1237.

Samani, Z., 2000. Estimating solar radiation and evapotranspiration using minimum climatological data. Journal of Irrigation and Drainage Engineering 126 265-267.

Samani, Z., 2004. Discussion of "History and evaluation of Hargreaves evapotranspiration equation" by George H. Hargreaves and Richard G. Allen. Journal of Irrigation and Drainage Engineering, ASCE 130 (5), 447-448.

Shen, S.S.P., Dzikowski, P., Li, G., Griffith, D., 2001. Interpolation of 1961-97 daily temperature and precipitation data onto Alberta polygons of Ecodistrict and Soil Landscapes of Canada. Journal of Applied Meteorology 40, 2162-2176.

Shepard, D.,1968. A two-dimensional interpolation function for irregularly-spaced data. In: Proceedings of 1968 ACM National Conference. ACM, New York pp. $517-524$

Smith, M., 2000. The application of climatic data for planning and management of sustainable rainfed and irrigated crop production. Agricultural and Forest Meteorology 103, 99-108.

Thornthwaite, C.W., 1948. An approach toward a rational classification of climate. Geographical Review 38 (1), 55-94.

Todorovic, M., Karic, B., Pereira, L.S., 2013. Reference evapotranspiration estimate with limited weather data across a range of Mediterranean climates. Journal of Hydrology 481, 166-176.

Tsakiris, G., Pangalou, D., Vangelis, H., 2007. Regional drought assessment based on the reconnaissance drought index (RDI). Water Resources Management 21, 821-833.

UNEP, 1997. World Atlas of Desertification, 2nd ed. United Nations Environment Programme, Arnold, London, pp. 182.

Willmott, C.J., Mastuura, K., 1995. Smart interpolation of annually averaged air temperature in the united states. Journal of Applied Meteorology 34 2577-2586.

Willmott, C.J., 1981. On the validation of models. Physical Geography 2, 184 194.

Yatagai, A., Arakaw, O., Kamiguch, K., Kawamoto, H., Nodzu, M.I., Hamada, A., 2009. A 44-year daily gridded precipitation dataset for Asia based on a dense network of rain gauges. SOLA 5, 137-140.

Yatagai, A., Xie, P., Alpert, P., 2008. Development of a daily gridded precipitation data set for the Middle East. Advances in Geosciences 12, 165-170.

Zaitchik, B.F., Evans, J.P., Smith, R.B., 2007. Regional impact of an elevated heat source: the Zagros plateau of Iran. Journal of Climate 20, 4133-4146. 